\title{
Next-generation DNA sequencing-based assay for measuring allelic expression imbalance (AEI) of candidate neuropsychiatric disorder genes in human brain
}

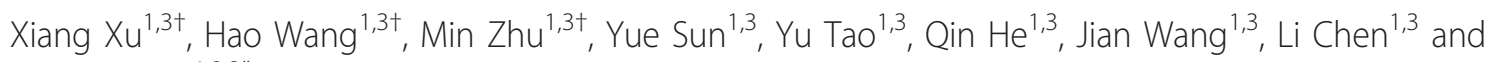
David Saffen ${ }^{1,2,3^{*}}$

\begin{abstract}
Background: Common genetic variants that regulate gene expression are widely suspected to contribute to the etiology and phenotypic variability of complex diseases. Although high-throughput, microarray-based assays have been developed to measure differences in mRNA expression among independent samples, these assays often lack the sensitivity to detect rare mRNAs and the reproducibility to quantify small changes in mRNA expression. By contrast, PCR-based allelic expression imbalance (AEI) assays, which use a "marker" single nucleotide polymorphism (mSNP) in the mRNA to distinguish expression from pairs of genetic alleles in individual samples, have high sensitivity and accuracy, allowing differences in mRNA expression greater than 1.2-fold to be quantified with high reproducibility. In this paper, we describe the use of an efficient PCR/next-generation DNA sequencing-based assay to analyze allele-specific differences in mRNA expression for candidate neuropsychiatric disorder genes in human brain.
\end{abstract}

Results: Using our assay, we successfully analyzed AEl for 70 candidate neuropsychiatric disorder genes in 52 independent human brain samples. Among these genes, 62/70 (89\%) showed AEI ratios greater than $1 \pm 0.2$ in at least one sample and 8/70 (11\%) showed no AEl. Arranging $\log _{2} \mathrm{AEI}$ ratios in increasing order from negative-topositive values revealed highly reproducible distributions of $\log _{2} A E I$ ratios that are distinct for each gene/marker SNP combination. Mathematical modeling suggests that these $\log _{2} A E I$ distributions can provide important clues concerning the number, location and contributions of cis-acting regulatory variants to mRNA expression.

Conclusions: We have developed a highly sensitive and reproducible method for quantifying AEl of mRNA expressed in human brain. Importantly, this assay allowed quantification of differential mRNA expression for many candidate disease genes entirely missed in previously published microarray-based studies of mRNA expression in human brain. Given the ability of next-generation sequencing technology to generate large numbers of independent sequencing reads, our method should be suitable for analyzing from 100- to 200-candidate genes in 100 samples in a single experiment. We believe that this is the appropriate scale for investigating variation in mRNA expression for defined sets candidate disorder genes, allowing, for example, comprehensive coverage of genes that function within biological pathways implicated in specific disorders. The combination of AEI measurements and mathematical modeling described in this study can assist in identifying SNPs that correlate with mRNA expression. Alleles of these SNPs (individually or as sets) that accurately predict high- or low-mRNA expression should be useful as markers in genetic association studies aimed at linking candidate genes to specific neuropsychiatric disorders.

* Correspondence: saffen@fudan.edu.cn

† Contributed equally

${ }^{1}$ Institutes of Brain Science, Fudan University, 138 Yixueyuan Road, Shanghai

200032, China

Full list of author information is available at the end of the article 


\section{Background}

Neuropsychiatric disorders are complex diseases that are strongly influenced by genetic, epigenetic, and environmental factors [1]. One of the central challenges in current psychiatric research is to determine the contributions of these factors to major neuropsychiatric disorders and use this knowledge to develop effective strategies for disease diagnosis, treatment and prevention.

Beginning with the elucidation of a consensus DNA sequence of the human genome and extending through current efforts to exhaustively document genetic variability in human populations, much has been learned about the genes and genetic variants that contribute to major neuropsychiatric disorders, such as schizophrenia [2,3], Alzheimer's disease $[4,5]$ and drug addiction $[6,7]$. Unlike Mendelian disorders, however, which can often be traced to mutations that disrupt gene structure or coding sequences, genetic markers that associate with complex disorders often map to chromosomal sites located outside of gene coding regions [8]. Such observations suggest that genetic variants that regulate gene expression, rather than disrupt gene structure, may be a major source of liability for, or protection from, complex disorders $[8,9]$.

Because of their potential importance for explaining the etiology and phenotypic diversity of complex diseases, there is currently great interest in developing methods for identifying regulatory genetic variants $[10,11]$. Unlike coding region mutations or chromosomal rearrangements, which can be identified by DNA sequencing alone, detection of regulatory variants requires experimentation, such as measurements of variation in mRNA expression or splicing. To meet this challenge, hybridization-based microarray assays have been developed that are capable of measuring variation in the expression of hundreds-to-thousands of genes in multiple samples in a single experiment $[12,13]$.

While microarrays have provided important information concerning variation in mRNA expression in a variety of tissues and cell lines and have the potential to identify both cis- and trans-acting regulatory variants $[14,15]$, they are not necessarily the best choice for analyzing mRNA expression in human brain. When used to compare mRNA expression among independent samples, microarray-based assays typically require large numbers of samples to obtain statistically significant correlations between genetic variants and mRNA expression and, in the absence of a cDNA PCR amplification step, often lack the sensitivity to detect rare mRNAs [16-18]. The requirement for large numbers of samples to attain statistical significance is closely related to the large variation in mRNA expression among samples that is determined by non-genetic factors. This is particularly a problem for studies of mRNA expression in human brain, since the quality of mRNA isolated from autopsy brain tissue often varies among samples and the individuals that provided the samples differ in ages, sex, medical history, drug use and cause of death. Thus, variation in mRNA expression caused by regulatory genetic variants is often obscured, especially in small collections of unmatched samples.

In contrast to assays that involve comparisons between independent samples, assays that measure allele-specific differences in mRNA expression have the advantage that the relative level of mRNA expression from each genetic allele is determined within individual samples, with each autosomal allele serving as a control for the other [19-21]. Combined with PCR-based-amplification of cDNA reverse-transcribed from mRNA, this approach has produced highly accurate measurements of differential mRNA expression in a variety of human tissues, including brain, and provided important information about cis-acting genetic variants that regulate mRNA expression [22-34]. To date, however, only assays of low-throughput design have been used for allele-specific measurements of mRNA expression in human brain.

In this paper we describe a medium-throughput method for assaying allele-specific mRNA expression based on PCR amplification and next-generation DNA sequencing technology. Our results show that this assay produces allelic expression imbalance (AEI) ratios (defined as the ratio of the amount of mRNA derived from one genetic allele, divided by the amount of mRNA derived from the other allele) for mRNAs expressed in human brain of outstanding quality and reproducibility.

After measuring AEI ratios for many candidate genes, we noticed that graphs of $\log _{2} \mathrm{AEI}$ ratios ordered from most-negative to most-positive produced distribution patterns that are characteristic for each gene/marker SNP pair. Mathematical modeling of these $\log _{2} \mathrm{AEI}$ distributions revealed that they can be a rich source of information concerning the genetic variants that regulate mRNA expression for each gene. We believe that, used together, our AEI assay and mathematical modeling provide powerful tools for identifying regulatory genetic variants that contribute to major neuropsychiatric disorders.

\section{Results}

Next generation DNA sequencing-based AEI assay

An outline of our AEI assay is shown in Figure 1. Experimental details are provided in Methods, Table 1, Additional file 1, Figures S1 - S6, and Additional file 2, Tables S1 - S6. Briefly, genomic DNA (gDNA) isolated from small ( $\sim 30 \mathrm{mg})$ samples of frozen human brain was used for both genotyping and as a control for cDNA-based AEI measurements. To facilitate our long-term goal of screening several-hundred neuropsychiatric disorder 


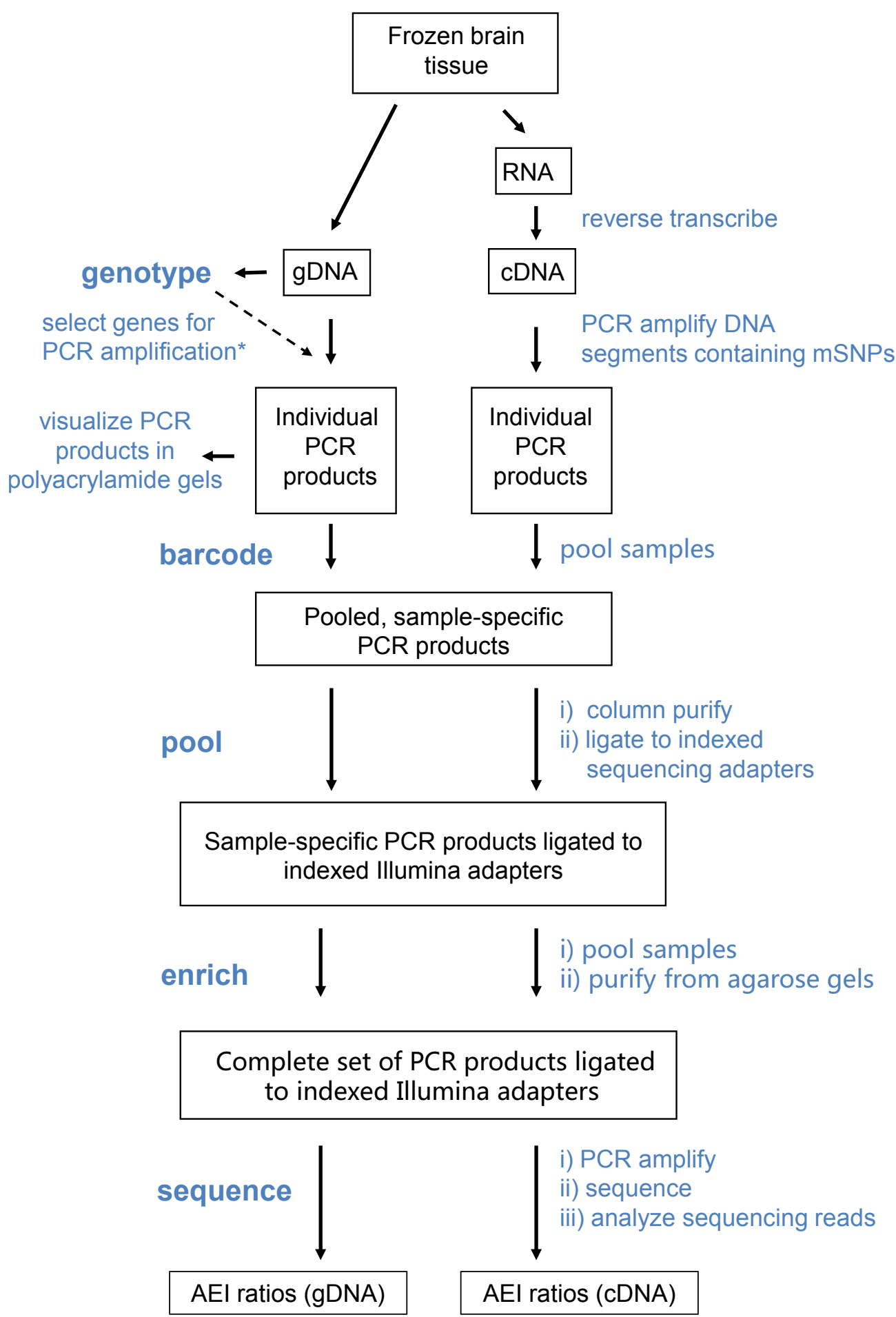

Figure 1 Flow diagram for AEl assays. Technical details are provided in Methods and Table 1 in the text and Additional file 1, Figures S1 - S5 and Additional file 2, Tables S1-S6.

candidate genes, we carried out genomewide genotyping for each of the 52 brains in our collection using Illumina HumanOmni1-Quad microarrays. For most genes, this information allowed us to infer the genotype of suitable
mRNA marker SNPs (mSNPs) for most of our candidate genes. SNaPshot ${ }^{\mathbb{B}}$ Multiplex kits (ABI) were used to genotype mSNPs not included or tagged by SNPs on the Illumina arrays. 
Table 1 Numerical summary for Illumina Assay-2

\begin{tabular}{ccc}
\hline Stage & gDNA/RNA & Number \\
\hline 0 & Candidate genes & 74 \\
0 & Independent brain samples & 52 \\
0 & Genotypes & $52 \times 1.14 \times 10^{6}$ \\
1 & Isolated gDNA/CDNA & $2 \times 52$ tubes \\
2 & Individual PCR products & 2762 tubes \\
$2^{\prime}$ & Supplemental PCR products & $\sim 200$ tubes \\
3 & Pooled, sample-specific PCR products & $2 \times 52$ tubes \\
4 & Sample-specific PCR products ligated to indexed Illumina adapters & $2 \times 52$ tubes \\
5 & Complete set of PCR products ligated to indexed Illumina adapters & $2 \times 1$ tube \\
6 & AEl Ratios & $1,371 \mathrm{gDNA}$ \\
& & 1,313 CDNA \\
\hline
\end{tabular}

For each candidate gene, gene-specific PCR primers were used to amplify segments of gDNA or cDNA that contain the corresponding $\mathrm{mSNP}$. To reduce the total number of PCR reactions, only gDNA and cDNA from brain samples heterozygous for the mSNPs were used as templates. To simplify the generation and analysis of the PCR reaction products, PCR amplifications of individual genes were carried out in sets, with each sample-primer combination in an individual tube. In all, 74 sets (one for each of the 74 candidate genes) comprising 3 to 36 gDNA template-based and 3 to 36 cDNA templatebased reaction mixes were independently amplified (total: 2,762 reactions).

To ascertain the efficiency of the PCR amplifications, aliquots from each reaction mix were resolved by electrophoresis in $15 \%$ polyacrylamide gels, and the intensity and purity of the PCR products examined by ethidium bromide staining. Approximately $93 \%$ of the samples yielded robustly stained, single PCR products. In cases where staining of PCR products with the predicted molecular weight was weak, additional PCR reactions $(\sim 200)$ were carried out to increase the amount of PCR products carried to the next step and to ensure that a sufficient number of mRNA molecules were sampled to obtain meaningful AEI ratios (see Methods for details).

Following confirmation of amplification, approximately equal amounts of PCR products (one PCR product for each gene with a heterozygous $\mathrm{mSNP}$ ) derived from a single brain sample were pooled, purified using QIAEXII beads and ligated to an indexed Illumina adapter coding for that sample (total: 52 gDNA template-derived samples + 52 cDNA template-derived samples). The ligated PCR products from all of the brain samples were pooled (total: one gDNA template-derived sample + one cDNA template-derived sample) and resolved by electrophoresis in $3 \%$ agarose gels. Ligation products in the appropriate size range $(150-220 \mathrm{bp})$ were excised from the gels and used as templates for PCR amplification with Illumina Primers 1.1 and 1.2 (see Additional file 1, Figure S1). The resulting PCR products were sequenced using an Illumina Genome Analyzer 2.0. The above procedure (with minor modifications) was independently carried out twice (Illumina Assay-1 and Illumina Assay-2) for a subset of genes and brain samples, beginning from the isolation of gDNA and total RNA.

Following sequencing, reads were sorted, collated and tabulated for calculation of AEI ratios using a custom computer program, as described in Methods and Additional file 1, Figure S2. As shown in Additional file 1, Figure S3, approximately $85 \%$ of the sequencing reads were full-length $(76 \mathrm{bp})$. Overall, approximately $60 \%$ of the reads survived quality-control triage and were used for the calculation of AEI ratios (Illumina Assay-2). In total, we obtained approximately $6 \times 10^{6}$ useable, independent reads for gDNA-derived sequences ( 1 flow cell lane) and $7 \times 10^{6}$ reads for cDNA-derived sequences $(2$ lanes) in Assay-1 and $13.2 \times 10^{6}$ reads for gDNA-derived sequences (2 lanes) and $18.5 \times 10^{6}$ reads for cDNAderived sequences (5 lanes) in Illumina Assay-2. For the second assay, the number of reads/sample for individual genes (i.e., the total reads for $\mathrm{M}+\mathrm{m}$ alleles) ranged from 1,079 to 33,250 for gDNA-derived sequences (average $=$ 9,911 ) and from 1,277 to 75,440 for cDNA-derived sequences (average $=14,919$ ) (data from Additional file 2, Table S5).

An important application of gDNA-based AEI measurements is the quantification of allele-specific bias that occurs during the PCR-amplification of gDNA and cDNA segments containing the marker SNP. As shown in Additional file 1, Figure S5, significant allele-specific amplification bias for gDNA templates was observed for most genes, with occasional genes showing greater than 1.5 -fold differences in amplification between alleles. This type of bias has been previously observed in PCR-based AEI assays [21,30,31].

One documented source of allele-specific PCR amplification bias is the use of PCR primers that bind to sites containing a SNP [35]. As listed in Additional file 2, 
Table S6, nine of our gene-specific PCR primers bind DNA sequences containing nominal SNPs listed in the NCBI SNP database. Three of these SNPs, however, have 0 or very low heterozygosity in the Han Chinese population and therefore should not present a problem. One SNP has a heterozygosity of 0.162 , but did not produce a significantly distorted $\log _{2}$ AEI ratio. Among the remaining five genes, all with SNPs of unknown heterozygosity in the Chinese population, two showed significant deviation of $\log _{2}$ AEI values from 0 .

In addition to PCR amplification bias, the presence of pseudogenes, highly homologous genes or chromosomal duplications (e.g. copy number variants) can also distort genomic DNA AEI ratios. As described in Methods and Additional file 3, we belatedly found evidence for off-target sites in the human genome for the CYP2D6 and NTAN1 PCR primer sets. We found no evidence, however, for offtarget sites for any of the other PCR primer set used in our study. Following previous examples [21,30,31], we therefore corrected both gDNA and cDNA ratios by multiplying the AEI ratios by the inverse of the average gDNA-based AEI for each gene. A list of the correction factors used to normalize AEI ratios for each gene is provided in Additional file 2, Table S5.

In addition to providing a method for correcting AEI measurements for PCR amplification bias, gDNA-based AEI measurements also yield important information concerning experimental error. Because only heterozygous individuals were included in our final data sets, deviations of normalized gDNA AEI ratios from 1 (or $\log _{2}$ normalized ratios from 0) can be used to estimate this error. Two different approaches were used to estimate experimental error. In the first, we determined the distribution of normalized gDNA AEI ratios for the entire set of measurements and calculated the mean, standard deviation (SD) and standard error of the mean (SEM) [details provided in Additional file 3]. This analysis showed that $95 \%$ of the normalized gDNA AEI ratios lay within the interval 0.82 to 1.22 (or \pm 0.29 for $\log _{2}$ normalized gDNA AEI ratios). As described in Additional file 3, this estimate of experimental error was used to evaluate the presence or absence of AEI for each gene in each sample.

In the second method, also described in Additional file 3 , experimental error was estimated based upon a comparison of deviations of $\log _{2} \mathrm{AEI}$ values from zero for normalized gDNA AEI ratios as a function of the number of sequencing reads used to calculate each ratio. As shown in Additional file 1, Figure S6(a), deviations from $\log _{2} \mathrm{AEI}=$ 0 , are greater than those predicted from a theoretical binomial sampling error curve, but still relatively small and decrease with increasing numbers of sequencing reads. The legend of Additional file 1, Figure S6(b) describes an empirical method for estimating the correlation between the number of sampling reads and experimental error that does not require assumptions about the statistical distribution of the error. As listed in Additional file 2, Table S4, we estimate the $\log _{2}$ experimental error to be about \pm 0.16 (i.e., linear AEI ratios between 0.895 and 1.117) for AEI measurements generated by 1,000 reads, \pm 0.10 (linear ratios between 0.93 and 1.07) for AEI measurements generated by 13,500 reads and \pm 0.09 (linear AEI ratios between 0.94 and 1.064) for AEI measurements generated by $>24,300$ reads. As described below, this method for evaluating experimental error was used in the mathematical modeling of $\log _{2}$ AEI population distributions.

\section{$\log _{2} A E I$ ratio distributions for 70 candidate neuropsychiatric disorder genes}

Figure 2 depicts representative results from our AEI assays for the three candidate neuropsychiatric disorder genes: (A) GAB2, (B) GNB1L and (C) DISC1. As shown in the figure, each of these genes produces robust cDNAbased $\log _{2}$ AEI ratios (blue), that vary considerably in extent and direction compared to gDNA-based controls (red). To facilitate analysis, the samples are ordered from low- $\log _{2}$ AEI to high- $\log _{2}$ AEI (left-to-right). When the data is arranged in this fashion, it is apparent that each gene displays a characteristic distribution of $\log _{2} \mathrm{AEI}$ ratios. As explained below, these distributions often reflect differences among the regulatory variants that produce AEI with respect to: i) allele-frequencies, ii) relative contributions to $\log _{2} \mathrm{AEI}$, and iii) degree of linkage to the mSNP.

Figure 3 provides a graphical overview of our AEI measurements for 70 genes. (Insufficient sequencing reads prevented calculation of AEI ratios for 3 of the original 74 candidate genes, and, as explained above, CYP2D6 was dropped due to co-amplification of CYP2D7a sequences.) Parts (a), (b) and (c) of the figure provide a key for interpreting the diagram in part (d). Figure 3(a) shows the relationship between linear AEI ratios and $\log _{2}$ AEI ratios. In general, expressing AEI ratios in the $\log _{2}$ form has the advantage that displacements of positive and negative $\log _{2}$ AEI ratios appear equal in magnitude, compared to graphs of linear ratios, which compress negative displacements. Figure 3(b and c) shows the color scheme for classifying $\log _{2}$ AEI ratios as negative, non-significant or positive. (The $\mathrm{mSNP}$ alleles in the numerator and denominator of each AEI ratio are listed in Additional file 2, Table S1.) In this Figure, cDNA $\log _{2}$ AEI ratios less than -0.29 or greater than +0.29 (corresponding to linear ratios less than 0.82 or greater than 1.22 ) were considered significant.

As seen in Figure 3(d) there is considerable variability in mRNA expression among the 70 candidate disorder genes, with measured cDNA $\log _{2}$ AEI ratios ranging from $-2.65(C Y F I P 1)$ to +2.79 (NGFR), corresponding to -6.27 and +6.9 -fold differences in expression between 
a

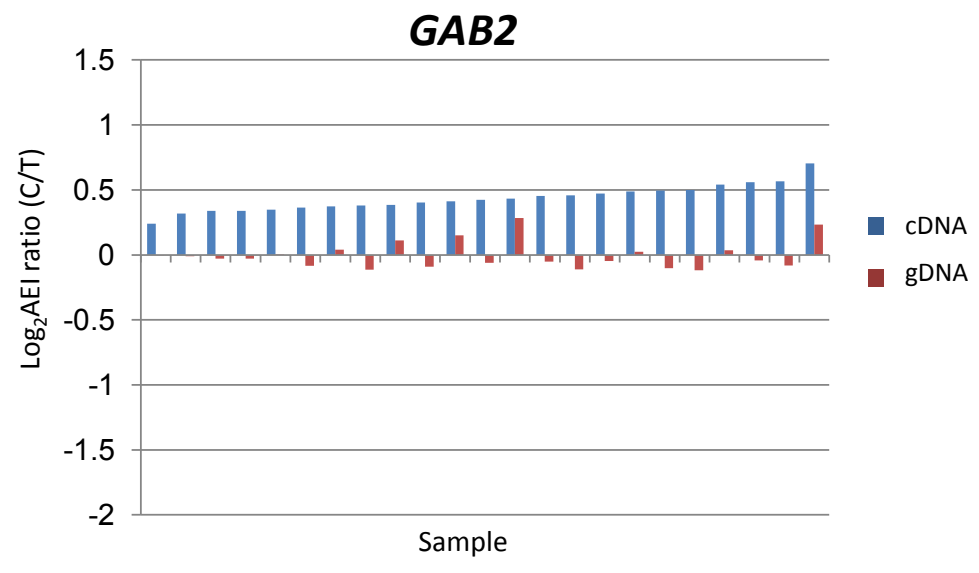

b

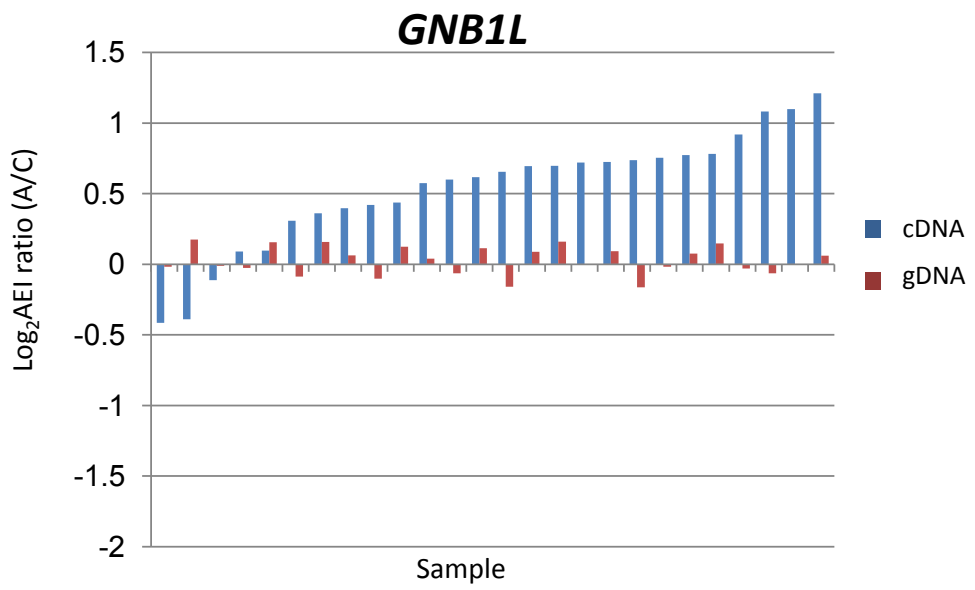

C

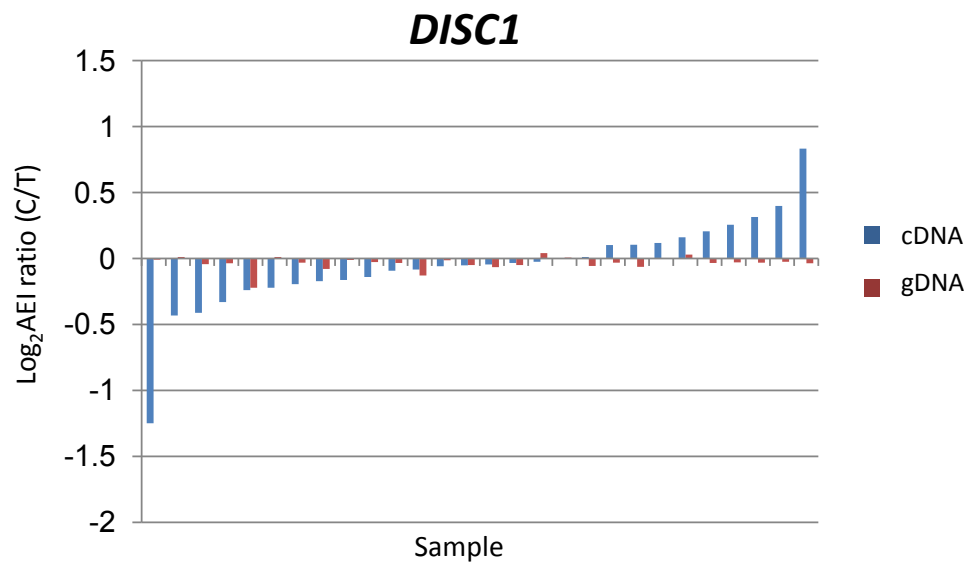

Figure 2 Representative $\log _{2} A E I$ distributions: GAB2, GNB1L and DISC1. Each pair of bars represents the gDNA-based (red) and cDNA-based (blue) $\log _{2} A E I$ ratios from a single sample. cDNA-based $\log _{2}$ AEl ratios are arranged in order from most- negative on the left to most-positive on the right, forming a distinct distribution of $\log _{2} A E I$ ratios for each gene. The selected genes illustrate three common patterns of $\log _{2} A E I$ population distributions: uniphasic, skewed and biphasic. As described in the text and in Additional file $4, \log _{2}$ AEl distributions often contain useful information concerning the number, location and linkage of the regulatory genetic variants that produce AEl in each gene. 


\section{a}

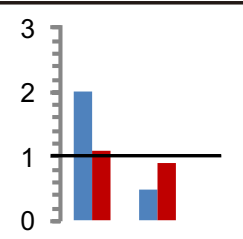

AEI
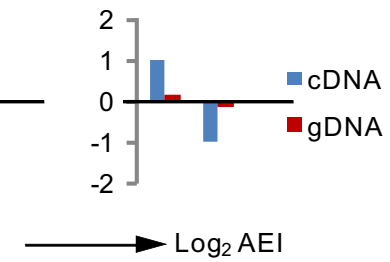

b

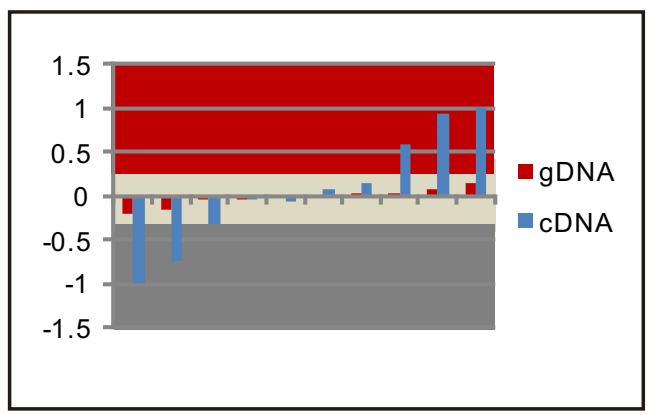

C

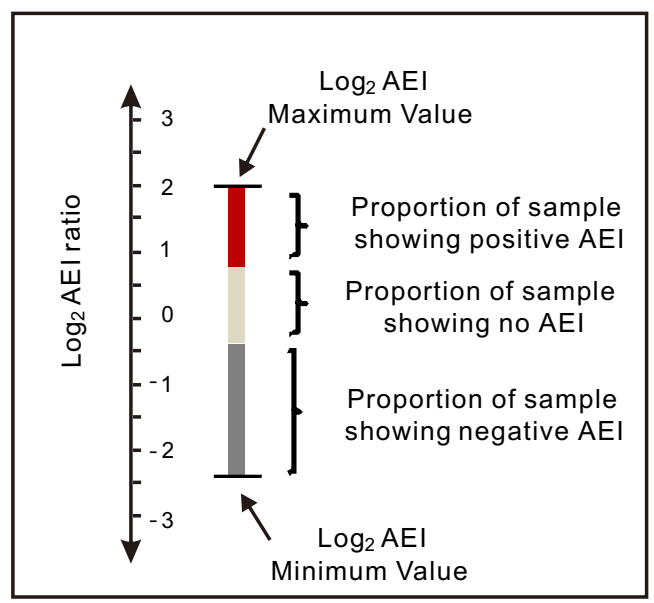

d

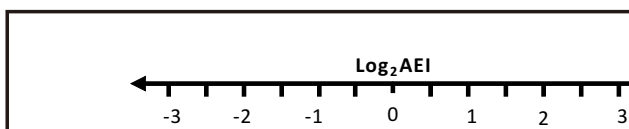

ADAM17

AGER

APBA2

ARVCF

$A R R B 2$

BACE1

BACE1

BACE2

$B D N F$
$C A L H M 1$

$\mathrm{CH} 25 \mathrm{H}$

CLU

CNR1

CNTNAP2

COMT

CYFIP1

DBH

DGCR14

DGCR 8

DISC1

DLG4

DRD1

DRD2

DRD 3

ERBB 4

ERBB
FOSB

$F O S B$
GAB2

GAB2
GABRB 3

GABRG3

GAL

GNB1L

GRIA2

GRIN2A

GRIN2B

GRN
GRM3

GRM3

GSK3B

HTR2A

HTR $3 B$

$L R P 1$

LRRK2

MAPT

MAPT

MCHR

MYT1L

NDE1

NGFR

NPY

NRXN1

NTRK2

OPRD 1

OPRM 1

OPRM
$P 25$

PDYN

PDYN

PICALM

PRRG4

PSEN1

PSEN2

RAI1

RAl1

SLC1A2

SLC1A2

SLC6A3

SORL 1

TBX1

TNFRSF1

TNFRSF 21

TNK1

ZNF804A

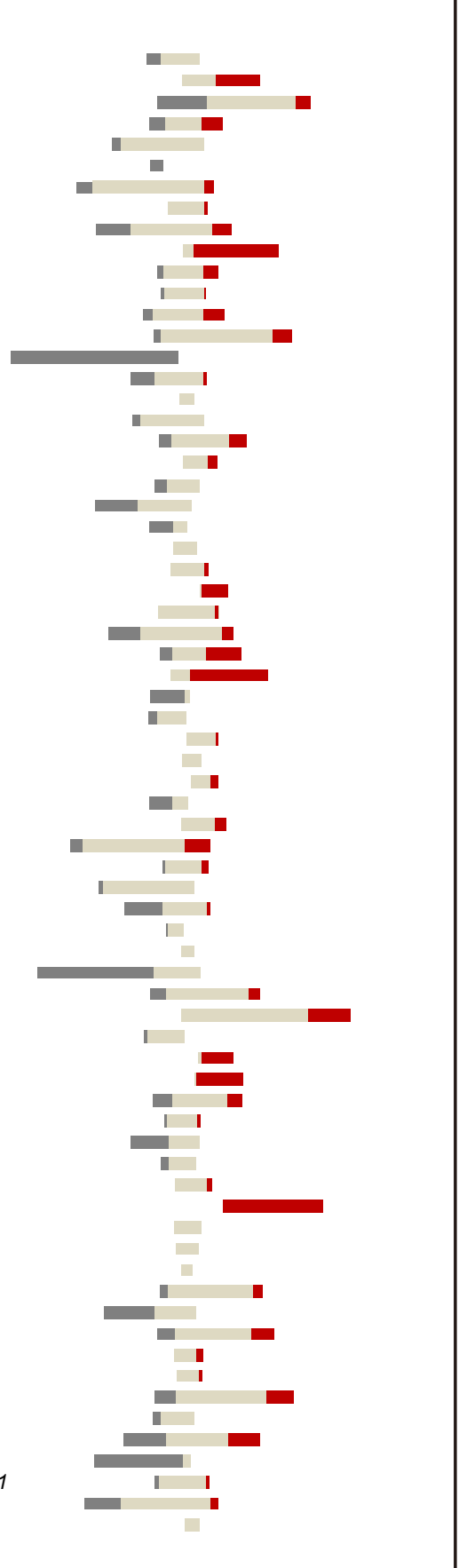

Figure 3 Summary of AEI results. Sections (a)-(c) provide keys for interpreting the diagram in (d), which summarizes the results of AEl measurements for 70 neuropsychiatric disorder candidate genes. The lengths of the grey, cream and red bars in (d) represent the percentage of samples with negative $\log _{2} A E I$ ratios, no significant AEl and positive $\log _{2} A E I$ ratios, respectively, for each candidate gene. The left-hand edge of each bar marks the smallest negative-AEI ratio and the right-hand edge the largest positive-log2 AEl ratio for the corresponding gene. Data used to produce this summary are provided in Additional file 2, Table S5. 
alleles, respectively. Figure 4 provides a summary of the results from Illumina Assay-2. Surprisingly, 89\% of our candidate genes show significant $\log _{2} \mathrm{AEI}$ ratios for at least one brain sample in our collection. Among samples heterozygous for the mSNPs for a particular gene, the proportion of samples with significant $\log _{2}$ AEI ratios ranged from $5 \%$ to $100 \%$, with an average of $36 \%$ and median $29 \%$.

\section{a}

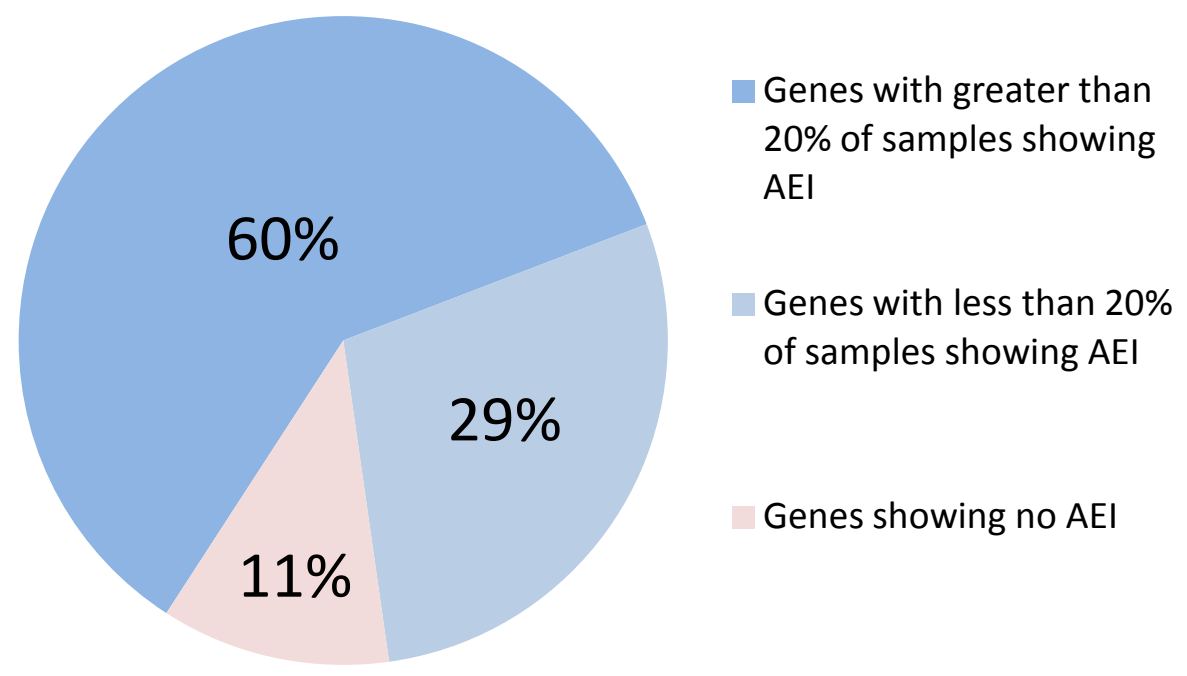

b

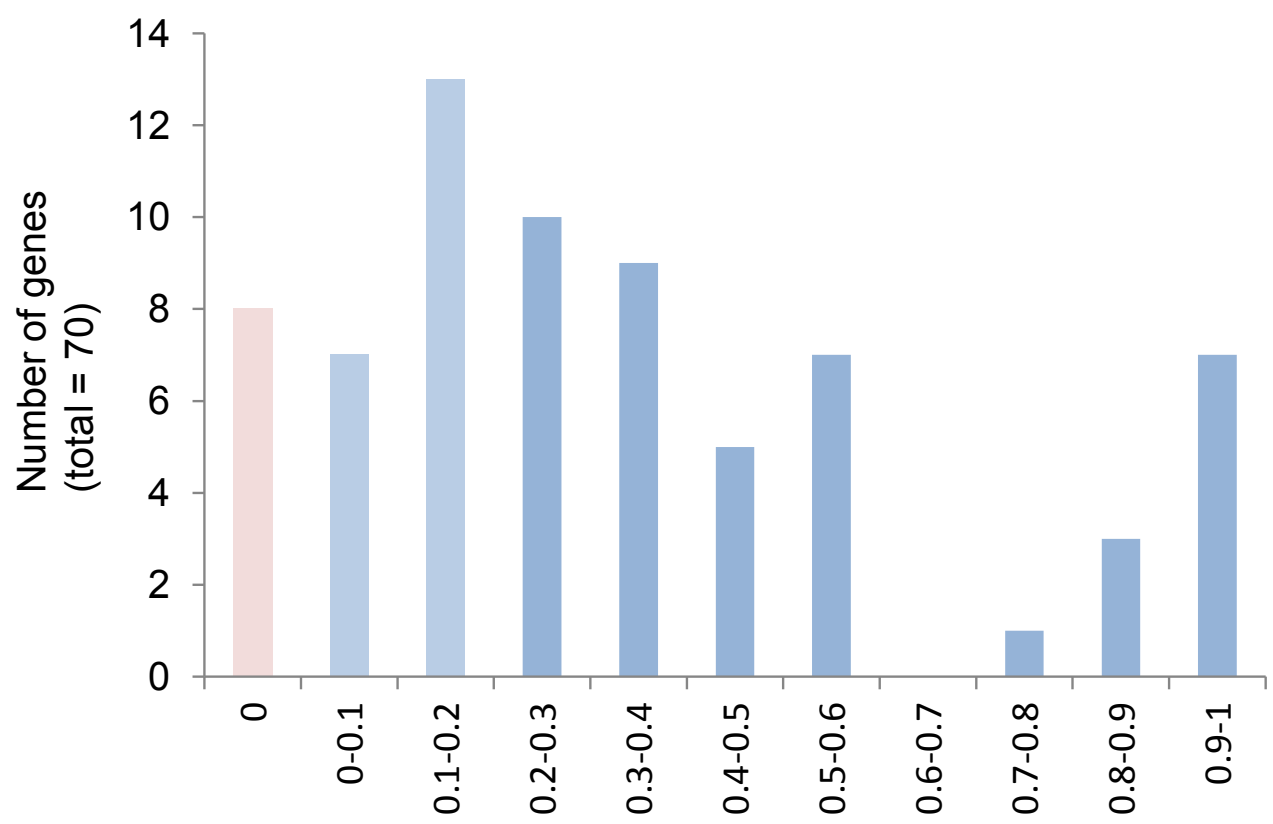

Proportion of brain samples showing AEI for each gene

Figure 4 AEI assay statistics. (a) Approximately 60\% (42/70) of our candidate genes produced significant AEl in at least 20\% of the 52 brain samples, 29\% (20/70) produced significant AEl in fewer than 20\% of the samples and 11\% (8/70) showed no AEl in any of the samples. (b) Histogram of the distribution of candidate gene with the indicated proportions of samples showing significant AEl. 
Figure 5(a) shows that excellent agreement was obtained for independent measurements of $\log _{2}$ AEI ratios for GNB1L. Figure 5(b) summarizes the results of comparisons of $\log _{2}$ AEI ratio measurements using our PCR/DNA sequencing-based assay for 40 candidate genes. More than eighty-percent (33/40) of these genes yielded satisfactory-to-excellent coefficient of determination $\left(r^{2}\right)$ values $(>0.7)$ when comparisons were analyzed by linear regression analysis. For some genes, low $\mathrm{r}^{2}$ values reflect the shape of their $\log _{2}$ AEI distributions (e.g., uniphasic, with a small range of $\log _{2}$ AEI values) or small sample number. Graphs showing the linear regression analysis of 12 representative genes are provided in Additional file 1, Figure S7. To further validate the results of our DNA sequencing-based assay, we independently measured AEI ratios for several genes using a $\mathrm{PCR} /$ primer-extension (SNaPshot ${ }^{\circledR}$ )-based assay, which has been extensively verified in previous studies [20,30,31]. Figure 5(c) shows excellent agreement between these two methods for GNB1L.

\section{Modeling $\log _{2} \mathrm{AEI}$ distributions}

As described above, $\log _{2}$ AEI distributions are characteristic for specific gene/mSNP pairs and highly reproducible. To better understand these patterns, we developed a simple mathematical model that can mimic distributions of $\log _{2}$ AEI ratios with surprising accuracy. Modeling the three candidate neuropsychiatric disorder genes $G A B 2$, GNB1L and DISC1 is briefly described in Additional file 4. A comprehensive description of this model will be presented in a separate paper (Sun Y, et al, manuscript in preparation).

According to our model, the shapes of $\log _{2}$ AEI distributions are influenced by: i) the number of cis- and transacting regulatory variants (rVar) [rVarA, rVarB, rVarC, rVarT, etc.], ii) their major allele frequencies $[\mathrm{P}(\mathrm{A}), \mathrm{P}(\mathrm{B})$, etc.] iii) the contribution of each variant to $\log _{2} \mathrm{AEI}$ ratios $[j, k, 1, m$, etc], iv) the degree of linkage disequilibrium between rVar's [D'(AB), etc.], v) the degree of linkage disequilibrium between each rVar and the mSNP [D'(AM), D'(BM), etc.] and vi) complex genetic, epigenetic or nongenetic factors.

A comparison of the predicted and experimentally determined $\log _{2}$ AEI distributions for GAB2, GNB1L and DISC1 is shown in Figure 6. In the case of GAB2, the observation that the $\log _{2}$ AEI ratios are all in the same (positive) direction suggests that mRNA expression is primarily regulated by single cis-acting regulatory variant that is in complete linkage disequilibrium with the mSNP. By contrast, the skewed $\log _{2}$ AEI distribution obtained for $G N B 1 L$, in combination with a gradient in $\log _{2}$ AEI values and the presence of several samples with negative or nonsignificant $\log _{2}$ AEI ratios, suggests that mRNA expression is regulated by two genetic variants, a cis-acting variant partially linked to the mSNP and the other unlinked or weakly linked to the mSNP. Finally, for DISC1, the nearly equally balanced, biphasic AEI population distribution, suggests the influence of multiple regulatory variants, which are all unlinked (or very weakly linked) to the mSNP. Details of the modeling of these genes are presented in Additional file 4 and a discussion of the results with respect to previously published studies is presented in Additional file 5.

\section{Discussion}

In this paper we describe a PCR/next-generation DNA sequencing-based method for quantifying allele-specific differences in mRNA expression and demonstrate that it produces detailed and highly reproducible information concerning the expression of candidate neuropsychiatric candidate genes in human brain. The two major strengths of our assay are the ability to: 1 ) reproducibly measure small differences in allelic expression for both common and rare mRNAs and 2) generate population distributions of $\log _{2}$ AEI ratios that are useful for generating testable hypotheses concerning the number, location and relative contributions of genetic variants that regulate mRNA expression.

When analyzing large numbers (50 - 200) of genes and samples $(50-100)$, the cost of our assay is approximately one-half and hands-on time approximately one-third that of low-throughput PCR/primer extension (SNaPshot ${ }^{\circledR}$ )based assays. The use of DNA-sequencing instead of $\mathrm{SNaPSh}^{\odot}{ }^{\odot}$-based primer-extension as the assay read-out obviates the gene-by-gene fine-tuning often required for $\mathrm{SNaPshot}$ assays, as well as the influences of differential efficiencies of incorporation of fluorescently labeled dideoxynuclotides into DNA and differences in the quantum efficiency of the fluorophores, which can distort AEI ratios. Experimental error in $\mathrm{SNaPshot}{ }^{\odot}$-based assays varies among genes and generally only allows quantification of AEI ratios greater than 1.2. By contrast, given sufficient numbers of sequencing reads, AEI ratios as low as 1.1 can often be reliably measured using our method.

Our AEI assay also compares favorably to previously developed high-throughput methods. Several studies have described AEI assays that are based on differential hybridization in microarrays [36-39]. While each of these assays is capable of detecting many thousands of differentially expressed transcripts in a single experiment, two of the studies $[36,38]$ reported that reliable AEI could only be detected for linear AEI ratios greater than 1.5. The other two studies $[37,39]$ described an assay that lacked a PCR amplification step, potentially limiting the ability to use the assay to measure AEI ratios for rare mRNA transcripts in brain.

In addition to microarray-based assays, high-throughput AEI assays based on PCR and second-generation 
a

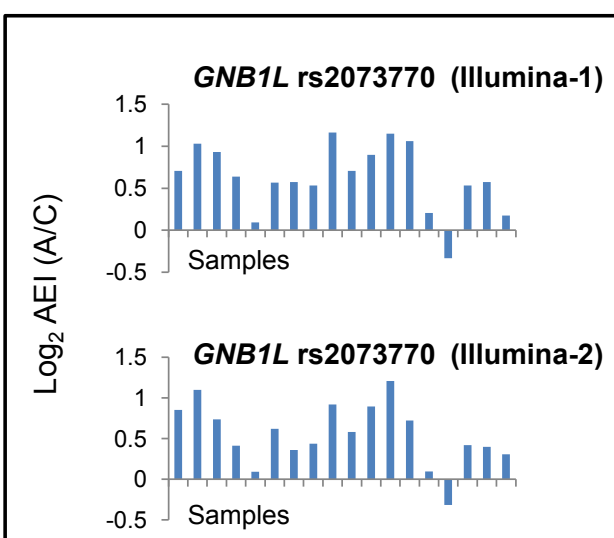

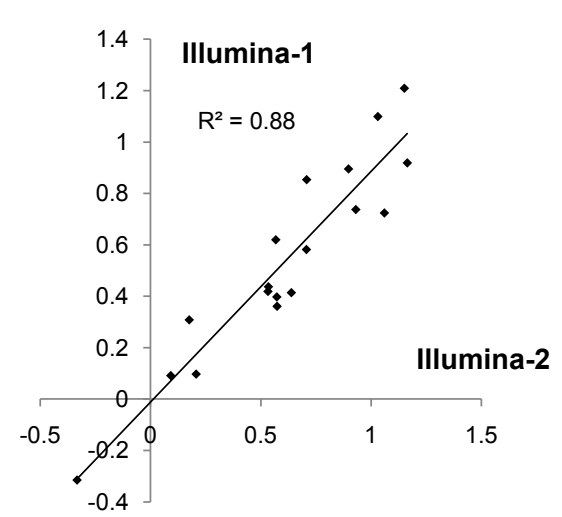

b

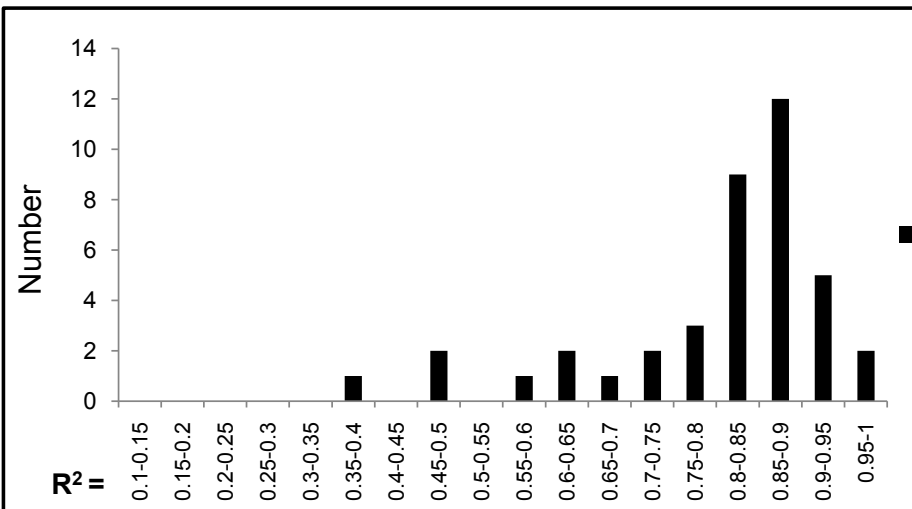

- Number of genes with the indicated $R$-squared value for two independent sets of AEI measurements (Total $=40$ genes $)$

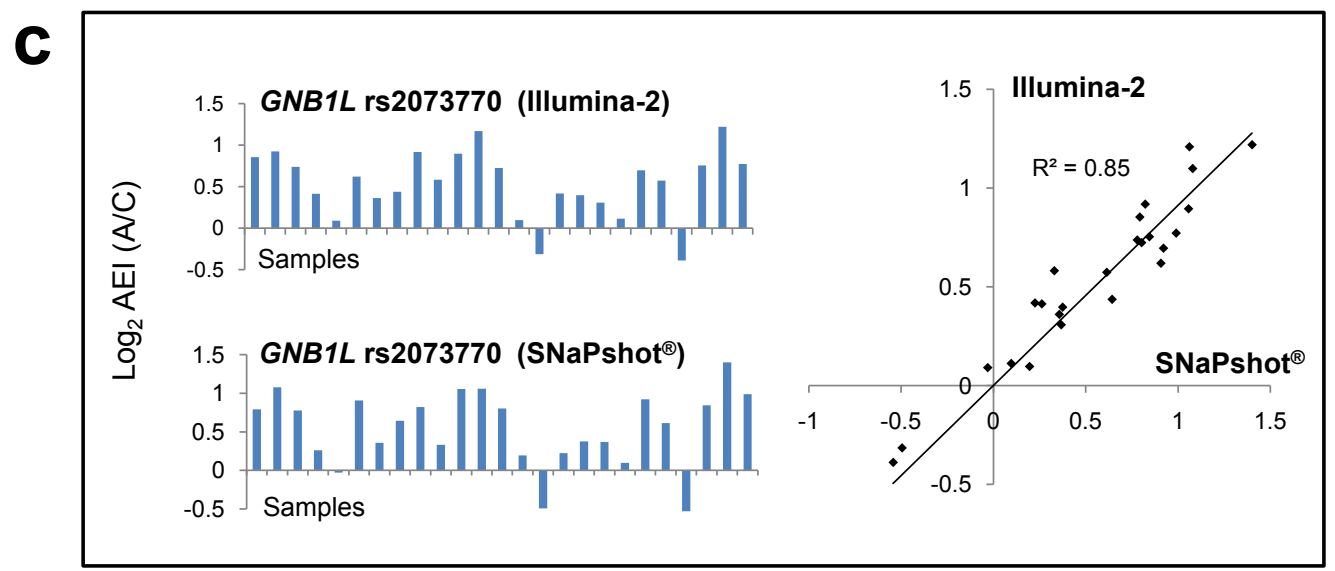

Figure 5 Reproducibility of AEI assays (GNB1L). (a) [Left] Comparison of the results of independent measurements of GNB1L AEl. (Each assay was performed independently, from the isolation of brain RNA through DNA sequencing.); [Right] Regression analysis. (b) Histogram of the distribution of $r^{2}$ values obtained in regression analysis of independent AEl assays for 40 candidate genes for which replica assays were carried out. (All data are shown). (c) [Left] Comparison of the results of independent measurements of GNB1L AEl using PCR/DNA sequencing-based (top) and PCR/SNaPShot ${ }^{\mathbb{B}}$-based (bottom) assays. [Right] Regression analysis. [Note: the Illumina-2 AEl ratios in (a) were matched with those obtained in the Illumina-1 AEl assay, which contained fewer samples. The full set of data from the Illumina-2 assay is shown in (c).] 


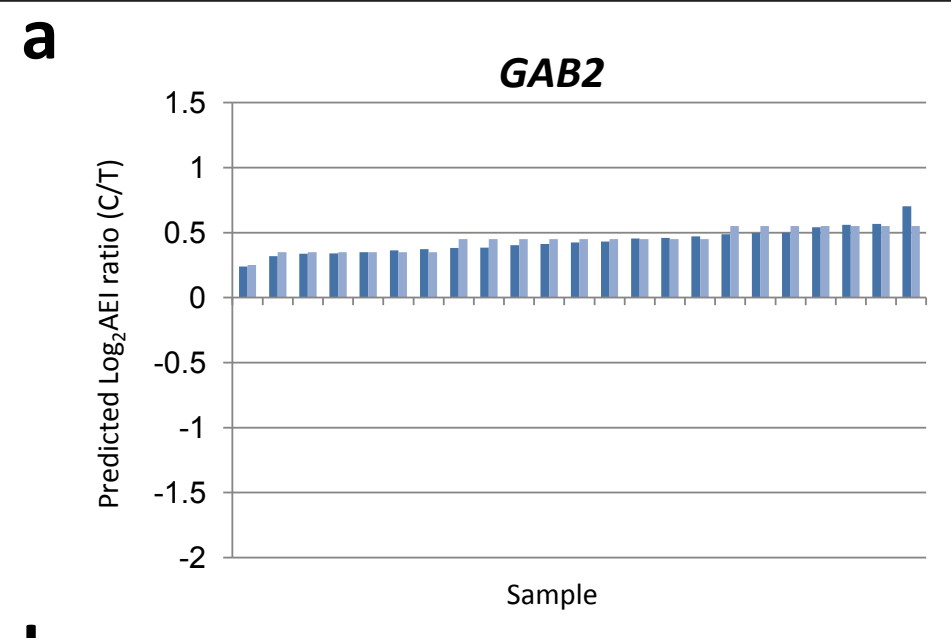

b

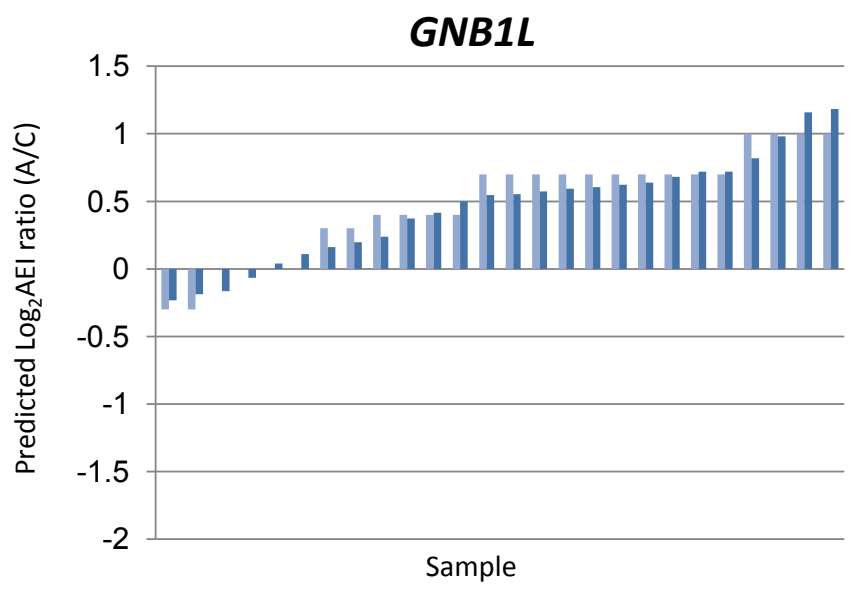

C

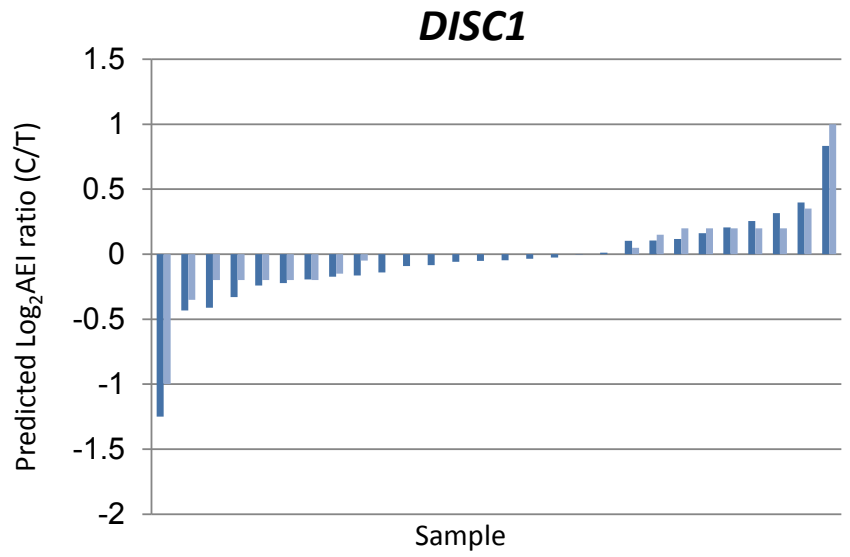

Figure 6 Modeling $\log _{2} A E I$ population distributions. Predicted $\log _{2} A E I$ distributions for (a) GAB2, (b) GNBIL and (c) DISC1 were calculated using the mathematical models described in Additional file 4. For each gene, the population frequency of the mSNP, P(M), was experimentally determined for our collection of samples. Dark blue: experimental data; light blue: predicted $\log _{2} \mathrm{AEI}$ ratios.

DNA sequencing have also recently been described [40-42]. Main BJ et al. [40] developed an AEI assay similar in design to ours, which they successfully used to analyze cis- and trans-regulation of five Drosophila simulans genes. Zhang $\mathrm{K}$ et al. [41] and Lee et al [42] established a "digital RNA allotyping" assay, based on deep sequencing of "padlock" oligonucleotide probes designed to distinguish alleles of 27,000 exonic SNPs 
(minor allele frequency $>0.07$ ). In this assay, genotyping calls were based on a minimum of 20 sequencing reads and AEI ratios for mRNAs expressed in human cells were based on a minimum of 50 sequencing reads.

Several additional studies have used whole transcriptome sequencing (RNA-seq) $[43,44]$ strategies for genomic-scale detection of AEI [45-49]. Although this approach provides valuable information about the spectrum of mRNA in specific tissues, including information concerning the expression of splicing variants, the depth of coverage is usually not sufficient to obtain accurate AEI ratios. Although several studies calculated AEI ratios based on as few as 50 sequencing reads, Fontanillas et al. [48], using 454 sequencing technology to quantify mRNA expression in Drosophila, established that 500 to 1,000 sequencing reads are required to accurately quantify AEI ratios. This range is consistent with the results of our analysis of experimental error as a function of sequencing reads (Additional file 1, Figure S6 and Additional file 2, Table S4).

To date, three major studies have used microarray-based mRNA expression assays combined with genome-wide genotyping to quantify mRNA expression and identify eQTL's for genes expressed in human brain [16-18]. Although each of these studies yielded important information concerning mRNAs that could be detected, each also lacked the sensitivity to detect mRNAs for many important candidate disease genes.

Myers et al. [16] used the Illumina HumanRefseq-8 Expression BeadChip system to quantify levels of 14,078 transcripts in RNA isolated from 193 independent samples of human cortex. Screening SNPs located within approximately $2.1 \mathrm{M}$ bp chromosomal segments centered on each gene for correlations between genotype (additive model) with mRNA expression yielded significant associations for 433 SNP-transcript pairs (in 99 transcripts = $0.7 \%$ of detected mRNA transcripts), with the majority of the associated SNPs located within $70 \mathrm{~kb}$ of the transcript. Although each of these cis-associations was significant after correction for SNPs tested in the same region, only two genes, KIF1B and IPP, remained significant after corrections for multiple testing for all SNPs-transcript pairs that were studied. Furthermore, with the exception of MAPT [26], no genes previously demonstrated to exhibit AEI in human cerebral cortex in PCR-based AEI assays, including DTNBP1 [22], COMT [23], GNB1L [50], TBX1 [50], OPRM1 [28], DRD2 [29], and CHRNA5 [33] were included in the list of nominally significant cis SNPtranscript pairs.

In a follow-up study by the same group, Webster et al [17] used more stringent inclusion procedures for expressed transcripts, analyzing 8650 transcripts in 486 late-onset Alzheimer's disease (LOAD) cases and 279 control brain samples. Again, none of the AEI-positive genes listed above was correlated with a SNP located in the region of the gene, although a SNP located on chromosome 1 was weakly correlated with expression of GNB1L mRNA in the set of AD brain samples $\left(\mathrm{r}^{2}=\right.$ the contribution of SNP rs7527404 to the variance of transcript expression $=0.13$ ).

Using expression data from 269 brain samples available on the Stanley Medical Research Institute Online Genomics database (https://www.stanleygenomics.org), inhouse genotyping on Affymetrix Human Genome U133A microarrays, and careful pre-screening of the of the expression and genotyping data to eliminate the effects of confounding variables, Liu et al., [18] identified 903 SNPexpression probeset pairs (in 826 genes) that showed significant "region-wide" association (i.e., significant after correction for multiple testing of SNPs in the region of the gene for correlations between genotype and expression). Among these, 562 SNP-expression probeset pairs (in 106 genes) also showed significant "phenotype-wide" association (i.e., significant after correction for multiple testing for all genotype-expression correlations examined).

Although the study of Liu et al., identified more genes that are regulated by cis-acting genetic elements compared to the study of Myers et al., with the exceptions of GSTM3 [51] (significant at both the "region-wide" and "phenotype-wide" levels) and COMT [23] (significant at the "region-wide," but not the "phenotype-wide" level), genes previously shown in PCR-based assays to have significant AEI in human cortex were not detected. As noted by the authors, the microarray-based expression assays also did not detect mRNA levels sufficient for analysis for many additional neuropsychiatric disorder candidate genes.

Among the 70 genes examined in the present study, MAPT was reported by Myers et al. [16] to have significant P-values, but the remaining 69 were not detected. In addition to GNB1L, Webster et al. [17] reported correlations between transcript levels and trans-SNPs for an additional three of our candidate genes, $C L U, N P Y$ and PICALM, but no correlating cis-SNPs. In the study of Liu et al [18], four of our candidate genes, HTR2A, LRP1, NTAN1 and GRIA2, attained significant "region-wide" P-values, but not "phenotype-wide" P-values, 23 genes were not significant at either level, and 44 were not detected at levels sufficient for analysis.

Taken together, the results of these three studies strongly suggest that PCR-based mRNA expression assays will prove to be the method of choice for investigating genetic regulation of many important disease candidate genes in human brain. An important limitation of this method that should be mentioned, however, is that some candidate genes lack suitable mSNPs for AEI measurements or contain only mSNPs with very low heterozygosity. For such genes, the traditional approach of looking for 
correlations between relative mRNA expression (e.g., measured by real-time PRC) genotypes of candidate regulatory SNPs is the next-best option.

By contrast to previously published studies, our study suffers somewhat from an "embarrassment of riches" in that a very large percentage of our genes showed differential mRNA expression among the samples tested. For example, previous genome-wide studies of eQTL's and allele-specific expression (mostly in cell lines for transformed human lymphocytes) yielded estimates for differentially regulated genes in the range of $10-54 \%[52,53]$. By contrast, studies focusing on sets of candidate disease genes, have consistently detected higher percentages of genes showing AEI: greater than $50 \%[20,22,54]$. The observation that candidate genes are enriched for genes that show allele-specific differences in mRNA expression is consistent with the hypothesis that variation in gene expression contributes to susceptibility to complex diseases [10]. Consistent with this idea, a recent study showed that putative schizophrenia susceptibility alleles are enriched for alleles that influence mRNA expression in human brain [55].

In addition to focusing on leading candidate genes for schizophrenia, Alzheimer's disease and drug addition, another reason for the high percentage of genes showing AEI in our study is the accuracy of our assay, which allows small deviations from 1.0 to be detected with confidence. If experimental error based on sequencing read number is taken as the sole standard, our assay reliably detects AEI ratios was small as $1 \pm 0.1$. Taking \pm 0.1 as the cut-off, almost all of our 70 candidate genes show $\mathrm{AEI}$ in at least one sample. These observations suggest that small allele-specific deviations from 1.0 are nearly ubiquitous and raise the question concerning when allele-specific differences in mRNA expression become biologically meaningful.

Certainly the existence of AEI is not equally important for all genes. Rather, biologically important AEI is likely to be restricted to genes that encode proteins that are limiting for important biological processes. An example of such a gene is TPH2, which encodes tryptophan hydroxylase-2, the rate-limiting enzyme in the synthesis of serotonin in the brain [56]. For such "dose-sensitive" genes, even small changes in mRNA expression may have a significant biological effect, if the changes in mRNA are reflected in changes in protein level and/or enzymatic activity.

A good example of a dose-sensitive gene that does not encode an enzyme is APP, encoding amyloid precursor protein, the precursor of the toxic peptide $A \beta$, which accumulates in the brains of patients with Alzheimer's disease (AD) [57]. Duplication of the APP gene, as the result of rare chromosomal duplications or, as in the case of
Down's syndrome, duplication of the entire chromosome 21 , is strongly associated with early-onset AD [58]. Rare promoter mutations that modestly increase APP expression are also linked to early-onset AD [59]. If duplication of $A P P$, which may increase mRNA expression by $50 \%$, can have a dramatic effect on the risk and age of onset of $\mathrm{AD}$, it is not unlikely that smaller increases in mRNA expression, e.g., $10 \%-40 \%$, contribute to the more common late-onset $\mathrm{AD}$ (LOAD). The same argument holds for genes encoding enzymes and other proteins that function in the production, degradation, clearance and deposition of $A \beta$. Clearly analysis of as many genes as possible in these pathways and estimating their combined effects will be important to assessing the relative susceptibility to $\mathrm{AD}$. We believe that our assay provides the optimal balance between throughput and sensitivity that will be useful for investigating sets of genes that function within specific biological pathways implicated in $\mathrm{AD}$ and other neuropsychiatric disorders.

One of the major implications our AEI measurements and mathematical modeling is that, for many genes, mRNA expression is a "complex phenotype," involving 2, 3 or more cis-acting regulatory variants (or, in some cases, at least one cis-acting variant plus additional trans-acting variants). These results are consistent with detailed studies showing that specific genes are regulated by multiple cisand trans-acting variants [60-62]. Based upon our modeling, at least two cis-acting regulatory variants are required to account for the observed spectrum of GNB1L $\log _{2} \mathrm{AEI}$ ratios in our brain samples. This implies that predicting high- and low-expression mRNA will require the identification of two variants, or, alternatively, two "indicator" (i) SNPs that are tightly linked to these variants and accurately predict high- and low-mRNA expression. Haplotypes comprised of high-or low-expression alleles of regulatory variants or iSNPs would provide the best genetic markers to test the hypothesis that differential expression of GNB1L contributes to risk of developing schizophrenia. One of the major goals of our AEI studies is to identify the best possible genetic markers for association studies for this and other candidate neuropsychiatric disorder genes.

In summary, we believe that the AEI assay and molecular modeling described in this study will provide useful tools for investigating the genetic basis of complex diseases, including major neuropsychiatric disorders. These methods should be immediately useful for investigating, in a comprehensive manner, the possible contributions of genes that function within specific biological pathways and systems that contribute to disease. They should also be useful for comparing the regulation of specific genes in developing and mature brain [55], investigating regionand cell-type specific mRNA expression [63], integrating 
information about expression and splice variants [64,65] and investigating epigenetic mechanisms of gene regulation $[66,67]$.

\section{Conclusions}

In this study we describe a novel, PCR and next-generation DNA sequencing-based method for quantifying allelic expression imbalance (AEI) of mRNA expression in human brain. We show that this assay produced detailed and highly reproducible measurements of AEI ratios for 70 neuropsychiatric disease candidate genes. We also demonstrate that population distributions of $\log _{2}$-transformed AEI ratios for individual gene/marker SNP pairs can provide important information concerning the number, location and effect size of regulatory variants that influence mRNA expression. Taken together, our assay and mathematical modeling provide powerful tools for analyzing the genetic regulation of candidate disease genes and should be useful for investigating how regulatory genetic variants contribute to complex human disorders.

\section{Methods}

\section{Selection of Candidate genes and marker (m)SNPs}

Candidate genes for this study were selected based on their relevance to neuropsychiatric disorders currently under investigation in the Saffen laboratory: i) schizophrenia/autism, ii) Alzheimer's disease and/or iii) heroin addiction. Particular attention was given to genes that had been previously linked to one or more of these disorders in genetic association studies or are located within copy number variations (CNVs) that associate with schizophrenia and/or autism. To allow allele-specific quantification of mRNA expression, candidate genes mRNAs were required to contain at least one single nucleotide polymorphism (SNP) with high heterozygosity in the Han Chinese population for use as a marker SNP. Most of the selected candidate genes had not previously been tested for allelic expression imbalance (AEI) in human brain, although several previously studied genes were included for the purpose of comparison and verification. A list of the 74 genes included in this study can be found in Additional file 2, Table S1.

\section{Human Brain tissue}

Frozen sections of human brain from: i) prefrontal cortex (Brodmann Area 46), ii) hippocampus, iii) amygdala, iv) ventral striatum/nucleus accumbens, v) substantia nigra, and vi) rostral pons from 52 Han Chinese individuals were obtained from the Chinese Brain Bank Center (SouthCentral University for Nationalities, Wuhan, China). This sample population comprised 25 males and 27 females (ages: 1 to 70; average 41) and cause of death, included illness, traffic accidents, electronic shock and heart-attacks. Postmortem intervals were less than 36 hours (most less than 24 hours). In all cases, written consent for tissue donation was obtained from relatives (on file at CBBC). Use of human autopsy tissue is considered non humansubject research and is IRB exempt under NIH guidelines.

\section{Isolation of genomic DNA and total RNA}

Frozen brain tissue $(\sim 30 \mathrm{mg})$ was homogenized in $180 \mu \mathrm{l}$ of DNA lysis buffer $+20 \mu$ proteinase K (QIAamp ${ }^{\circledR}$ DNA Mini kit, Qiagen) and genomic DNA (gDNA) isolated, according to the instructions of the manufacturer (Qiagen, Valencia, CA, USA). For total RNA, frozen brain tissue $(\sim 100 \mathrm{mg})$ was homogenized in $(1 \mathrm{ml})$ Trizol reagent (Invitrogen, Carlsbad, CA, USA), and total RNA isolated as recommended by the manufacturer. Following resupension in $30 \mu \mathrm{l}$ RNAase-free water containing $2 \mu \mathrm{l}$ RNase$\mathrm{OUT}^{\mathrm{TM}}$ (Invitrogen), contaminating genomic DNA was eliminated by incubating at $37^{\circ} \mathrm{C}$ in the presence of $30 \mathrm{U}$ RNase-free DNase I (New England Biolabs) for $30 \mathrm{~min}$. The RNA was then purified using Qiagen RNeasy Mini kits, as recommended by the manufacturer, resuspended in $30 \mu \mathrm{l}$ RNAase-free water and stored at $-80^{\circ} \mathrm{C}$. The quantity of gDNA and total RNA was determined using a Nanodrop spectrophotometer (Thermo Inc). [Note: incubation of total RNA with large quantities of DNase I was required to prevent amplification of small genomic DNA sequences during PCR-amplifications using cDNA templates.]

\section{Genotyping}

Genomewide genotyping was carried out using HumanOmni1-Quad genotype arrays (Illumina) for each of the 52 independent samples in our study $\left(\sim 1.14 \times 10^{6}\right.$ genotypes/sample). For SNPs not included in these arrays, additional genotyping was carried out using SNaPshot ${ }^{\circledR}$ Multiplex kits (Applied Biosystems), as previously described [30,31]. Gene-specific PCR primers were designed using Oligo 6.0 (National Biosciences Inc., Plymouth, MN, USA) and synthesized by Sangon Biotech (Shanghai, China). For most genes, the same pairs of PCR primers (forward and reverse) were used for genotyping and amplification of cDNA sequences. Sequences of these primers are listed in Additional file 2, Table S2. In cases where forward and reverse PCR primers designed for amplifying cDNA sequences are located on different exons, alternative primer sets were used for genotyping and for measuring gDNA AEI ratios. These primers are labeled "G" in Table S2.

After completion of our experiments, we discovered that primer sets for two candidate genes, CYP2D6 and NTAN1, amplified off-target segments of DNA (see notes at the end of Additional file 2, Table S2). Because of possible conflation of genotyping and mRNA expression data with a highly homologous pseudogene, CYP2D6 was dropped from the list of "successfully analyzed" genes. By 
contrast, the NTAN1 primers failed to produce sufficient PCR products for AEI analysis. Analysis of primer sets for all the other candidate genes using NCBI's PRIMERBLAST (http://www.ncbi.nlm.nih.gov/tools/primer-blast/ ) and/or UCSCs In-silico PCR (http://genome.ucsc.edu/ cgi-bin/hgPcr?command=start) programs predicted amplification of only the intended target sequences.

\section{cDNA synthesis}

Complementary DNA was generated from $5 \mu \mathrm{g}$ total RNA in $20 \mu \mathrm{l}$ reaction mixes using SuperScript ${ }^{\circledR}$ III First Strand kits (Invitrogen, Carlsbad, CA, USA) and $1 \mu \mathrm{l}$ of $50 \mu \mathrm{M}$ oligo $(\mathrm{dT})_{20}$ primers, according to the directions of the manufacturer. cDNA reaction mixes were diluted $2 x$ with DNAase- and RNAase-free water (Sigma; final volume $40 \mu \mathrm{l})$ and stored at $-20{ }^{\circ} \mathrm{C}$ until use.

\section{Screening brain samples for expression of target mRNAs}

To obtain meaningful and reproducible AEI ratios, it is essential that the RNA samples contain a sufficient number of candidate gene mRNA molecules. Our previous experience suggests that a minimum of about 1,000 mRNA molecules is required to obtain stable AEI ratios for many genes, an estimate consistent with a recently published study [48]. To determine the appropriate brain section for assessing AEI of candidate genes, PCR amplification was first carried out using cDNA derived from purified prefrontal cortex RNA. Reaction mixes $(20 \mu \mathrm{l}$ total volume) included: $1 \mu \mathrm{l}$ cDNA (prepared as described above), $0.5 \mu \mathrm{M}$ (total) forward and reverse PCR primers, $0.8 \mathrm{mM}$ dNTP mix, 0.5 Units rTaq (Takara), and 1x PCR buffer (Takara). The amplification conditions comprised: $1 \mathrm{x}$ [ $94^{\circ} \mathrm{C}$ for $\left.5 \mathrm{~min}\right], 28-30$ cycles of [i) denaturation: $94^{\circ} \mathrm{C}$ for $30 \mathrm{sec}$; ii) annealing: $50-65^{\circ} \mathrm{C}$ for $45 \mathrm{sec}$ and iii) elongation: $72^{\circ} \mathrm{C}$ for $30 \mathrm{sec}$, followed by a final elongation $\left[72^{\circ} \mathrm{C}\right.$ for $\left.5 \mathrm{~min}\right]$ and short-term storage at $4^{\circ} \mathrm{C}$ or long-term storage at $-20^{\circ} \mathrm{C}$.

For genes that generated sufficient PCR products to produce strong, single bands on polyacrylamide gels (minimum $50 \mathrm{ng} / \mathrm{band}$ after 30 cycles from $5 \mu \mathrm{l}$ aliquot of PCR reaction mix), prefrontal cortical RNA was used for AEI analyses. For genes that did not yield sufficient PCR products (less than $50 \mathrm{ng} / \mathrm{band}$ after 30 cycles from $5 \mu \mathrm{l}$ aliquot of PCR reaction mix), PCR products from 2 to 3 independent cDNA synthesis reactions were pooled or RNA isolated from other brain regions was used as starting material. A list of the brain regions used for AEI analysis for each gene can be found in Additional file, Table S5. [Note: Assuming a PCR amplification efficiency of 2 and calculating backwards, $50 \mathrm{ng} /$ band $=200 \mathrm{ng}$ total PCR product obtained after 30 cycles can be estimated to derive from approximately 1,800 molecules of mRNA.]

\section{PCR amplification of genomic and CDNA segments containing mSNPs}

Segments of gDNA or cDNA containing mSNPs were PCR-amplified using 5'-phosphorylated oligonucleotide primers flanking the marker SNP. Gene-specific primer pairs were designed to generate PCR products 66 - $100 \mathrm{bp}$ in length, with mSNPs located approximately in the center. An upper limit of $100 \mathrm{bp}$ was chosen to ensure that mSNPs would be contained within 76 bp sequencing reads beginning from either end of the PCR product. The sequences of the gene-specific PCR primers are listed in Additional file 2, Table S2. PCR reactions mixes and amplification conditions are the same as those listed above. To minimize the total number of PCR amplifications, we used only genomic and cDNA templates from brain samples heterozygous for the mSNP for any particular candidate gene. A list of the number of brain samples heterozygous for the mSNP for each candidate gene is provided in Additional file 2, Table S5.

Following amplification, $5 \mu \mathrm{l}$ aliquots of the $20 \mu \mathrm{l}$ reaction mixes were resolved by electrophoresis on 15\% polyacrylamide gels and amounts of PCR products of the predicted size quantified using the Molecular Imager ${ }^{\mathbb{B}}$ XGel Doc XR+ System X with Quantity One ${ }^{\mathbb{R}} 1-\mathrm{D}$ Analysis Software (Bio-Rad Laboratories). Approximately equal amounts of PCR products derived from each candidate gene from a single brain sample were combined and purified using QIAEXII, according to the directions of the manufacturer (Qiagen, Valencia, CA, USA). Following resuspension in $40 \mu \mathrm{l}$ distilled water, the amounts of the pooled PCR products were quantified using a Nanodrop Spectrophotometer (Thermo, Inc). In all, $2 \times 52$ sets of pooled PCR products were prepared, two sets (i.e., one gDNA-derived and one cDNAderived) for each of the brains in our collection.

\section{Design and ligation of index-adapters}

Fifty-two double-stranded index-adapters were synthesized by Sangon Biotech (Shanghai). Each adapter contained a five-base pair index linked to Illumina adapter sequences. The five-base pair index sequences were designed following Craig DW et al. [68], with identical nucleotides at the $1^{\text {st }}$ and $5^{\text {th }}$ positions to provide redundancy. A list of the index sequences and corresponding sample numbers can be found in Additional file 2, Table S3. As shown in Additional file 1, Figure S1, one strand of each index-adapter contained an additional unpaired $\mathrm{T}$ residue at the 3 '-end, while the second strand was phosphorylated at the 5 '-end to facilitate ligation to the gene-specific PCR products.

The $2 \times 52$ sets of pooled PCR products $(1.5 \mu \mathrm{g}$ each) were independently ligated to 52 sets of indexed Illumina adaptors (3 $\mu$ g each) using T4 DNA ligase (New England Biolabs) at $16{ }^{\circ} \mathrm{C}$ overnight and then heated at $65{ }^{\circ} \mathrm{C}$ to 
inactivate the ligase. All of the ligation products were then combined into $2 \mathrm{x}$ one tube (i.e., one for gDNAderived PCR products and one for CDNA-derived PCR products) and purified and concentrated using QIAEXII beads. The pooled ligation products were resolved by electrophoresis on 3\% agarose gels. DNA fragments in the 150 to $220 \mathrm{bp}$ range were extracted from the gels using MiniElute Gel Extraction Kits (Qiagen).

\section{Final steps in DNA sample preparation}

To prepare the DNA fragments for sequencing, the ligated gDNA- and cDNA-derived DNAs were independently PCR-amplified using Illumina Primers 1.1 and 1.2 and Phusion DNA polymerase (Finnzymes Oy). The PCR products were resolved by electrophoresis on $15 \%$ polyacrylamide gels and DNAs of the appropriate size extracted using QIAquick Gel Extraction Kits (Qiagen). The concentration and purity of the DNAs were accessed spectrophotometrially (First run: gDNA sample $=55.8 \mathrm{ng} / \mu \mathrm{l} ; \mathrm{A}_{260} /$ $\mathrm{A}_{280}$ ratio $=1.85 ; \mathrm{cDNA}$ sample: $52.3 \mathrm{ng} / \mu \mathrm{l} ; \mathrm{A}_{260} / \mathrm{A}_{280}$ ratio $=1.89$; second run: gDNA sample $=38.2 \mathrm{ng} / \mu \mathrm{l} ; \mathrm{A}_{260} /$ $\mathrm{A}_{280}$ ratio $=1.91 ; \mathrm{cDNA}$ sample $=51.4 \mathrm{ng} / \mu \mathrm{l} ; \mathrm{A}_{260} / \mathrm{A}_{280}$ ratio $=1.91)$. A summary of the number of independent samples (tubes) required for each step in the preparation of DNA samples for sequencing in provided in Table 1.

\section{Illumina sequencing}

DNAs were prepared for sequencing on an Illumina Genome Analyzer 2.0 as described in the Single Read Cluster Generation Kit (v3) and SBS Sequencing Kit (v3) User Guides. Sequencing was carried out in the Laboratory of Epigenetics, Institutes of Biomedical Sciences, Fudan University. For Illumina assay-2, two flowcell lanes were used for sequencing gDNA-derived PCR products and five flowcell lanes for cDNA-derived PCR products. The average yield was $7.54 \times 10^{6}$ independent sequencing reads/lane, for a total of $52.8 \times 10^{6}$ independent reads. The distribution of read lengths is shown in Additional file 1, Figure S3(a).

\section{Data analysis}

As outlined in Additional file 1, Figure S2, sequencing data from the Illumina Genome Analyzer 2.0 was matched to a custom sequence library using BLAST 2.2.25 (NCBI). The library comprised all possible combinations of indices and candidate gene sequences (52 indices $\times 74$ genes $\times 2$ insert directions $=7,696$ reference sequences). Each sequencing read was transferred to a folder corresponding to its top match and sequences within each folder were aligned using MUSCLE 3.86 [69]. The SNP loci was then identified and the accuracy of the read classifications and alignments confirmed by comparing $20 \mathrm{bp}$ sequences upstream and downstream from the mSNP. The number of each mSNP allele was tabulated and AEI ratios calculated using the mSNP allele assignments (numerator and denominator) listed in Additional file 2, Table S1.

\section{Verification}

Reproducibility of AEI measurements were evaluated by linear regression analysis of $\log _{2}$ AEI ratios obtained in independent DNA-sequencing-based assays. For selected genes, AEI ratios were also determined using $\mathrm{SNaP}$ shot ${ }^{\mathbb{B}}$-based AEI assays, and the closes results evaluated by regression analysis. Representative examples of regression analysis are shown in Additional file 1, Figure S7. [Note: using regression analysis to compare replicate samples works well for $\log _{2} \mathrm{AEI}$ distributions that span a large range of values (negative to positive), but is not very informative for $\log _{2} \mathrm{AEI}$ distributions that span a small range of values. In addition, AEI ratios produced by low-frequency variants replicate poorly, when small numbers of samples are compared.]

\section{Additional material}

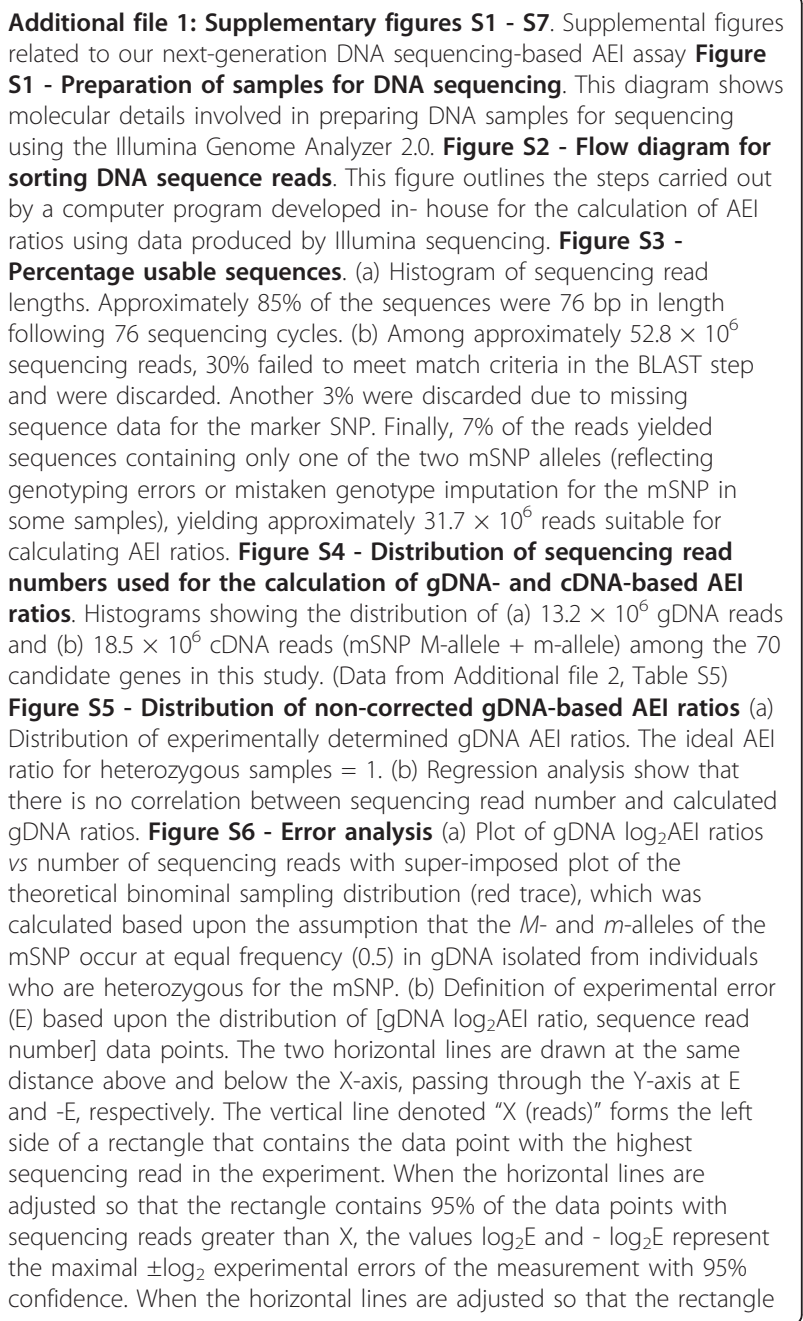


contains $99 \%$ of the data points with sequencing reads greater than $X$, the new values of $+\log _{2} E$ and $-\log _{2} E$ represent the maximum $\pm \log _{2}$ experimental errors at $99 \%$ with confidence. (c) Empirically determined correlations between experimental error $(E)$ and sequencing reads. $A$ custom computer program was used to calculate correlations between sequencing read number $(X)$ and $\pm \log _{2} E$ at $95 \%$ and $99 \%$ confidence levels. Figure S7 - Examples of correlations between independent AEI assays. Representative linear regression analyses for 15 candidate genes are grouped by level of statistical significance (P) for the correlation.

Additional file 2: Supplementary tables S1 - S6. Detailed information concerning our candidate neuropsychiatric disorder genes, PCR and sequencing primers, experimental error and measured AEI ratios. Table S1 - Neuropsychiatric disorder candidate genes. Table S2 - PCR primer sequences. Table S3 - Index sequences. Table S4 Estimation of Experimental Error. Table S5 - Data for AEl ratio measurements (Illumina Assay-2) Table S6 - SNPs within PCR primer binding sites.

Additional file 3: Correction factors for AEI ratios and criteria for the presence or absence of AEI in individual samples. A discussion of factors that influence the measurement of genomic DNA AEl ratios and criteria for assessing whether individual samples show allele-specific differences in mRNA expression.

Additional file 4: Modeling population distributions of $\log _{2} \mathrm{AEI}$ ratios. A brief outline of our method for modeling AEI ratios, including a description of the modeling of $\log _{2} A E l$ population distributions for GAB2, GNBIL and DISC1.

Additional file 5: GAB2, GNB1L and DISC1: AEl measurements and modeling. A discussion of inferences drawn from the modeling of GAB2, GNBIL and DISC1 in the context of previously published studies on the regulation of these genes.

\section{Acknowledgements and Funding}

We thank: Zhu Xiaoming (Fudan University) for help with DNA sample preparation; Lijun Xiong (Fudan University) for next-generation DNA sequencing, Jin Ke (Fudan University) and Yan Wu (Fudan University) for writing programs for the analysis of Illumina DNA sequencing reads, calculation of AEl ratios and estimation of experimental error, and Sun Dandan (Beijing Institute of Genomics) for writing a Perl script that enabled us to analyze our genotyping results in Haploview. This work was supported by the 985 Program of the Ministry of Education, the 973 Program of the National Basic Research Program of China: grants 2009 CB522007 and 2010 CB529601 and the National Science Foundation-China (NSFC): grants 30870899 and 81070908.

\section{Author details}

'Institutes of Brain Science, Fudan University, 138 Yixueyuan Road, Shanghai 200032, China. ${ }^{2}$ Key Laboratory for Medical Neurobiology, Fudan University, 138 Yixueyuan Road, Shanghai 200032, China. ${ }^{3}$ School of Biological Sciences, Fudan University, 220 Handan Road, Shanghai 200433, China.

\section{Authors' contributions}

$X X, H W, M Z$ : developed the DNA sequencing-based AEl assay, selected candidate genes, prepared DNA samples for sequencing and analyzed data for genes related to schizophrenia/autism, opioid addiction, and Alzheimer's disease, respectively; XX developed the methods for analyzing experimental error and defining the absence or presence of AEl. He also contributed to discussions concerning modeling $\log _{2} A E l$ population distributions. YS, YT, QH \& JW: prepared DNA samples for sequencing, analyzed AEl data and tested mathematical models for $\log _{2} A E I$ distributions. YS extensively assisted in modeling $\log _{2} A E l$ population distributions. LC helped design the DNA sequencing-based AEI assay and set up the SNPaShot ${ }^{\mathbb{B}}$-based AEI assays; DS: proposed and supervised the development of the DNA sequencingbased AEl assay, selected candidate genes, developed the mathematical model for $\log _{2} \mathrm{AEI}$ distributions, analyzed data and wrote the paper. All authors read and approved the final manuscript.
Received: 9 June 2011 Accepted: 20 October 2011

Published: 20 October 2011

Burmeister M, McInnis MG, Zollner S: Psychiatric genetics: progress amid controversy. Nature reviews 2008, 9(7):527-540.

2. Wray NR, Visscher PM: Narrowing the boundaries of the genetic architecture of schizophrenia. Schizophrenia bulletin 2010, 36(1):14-23.

3. Kim Y, Zerwas S, Trace SE, Sullivan PF: Schizophrenia genetics: where next? Schizophrenia bulletin 2011, 37(3):456-463.

4. Bertram L, Lill CM, Tanzi RE: The genetics of Alzheimer disease: back to the future. Neuron 2010, 68(2):270-281.

5. Ballard C, Gauthier S, Corbett A, Brayne C, Aarsland D, Jones E: Alzheimer's disease. Lancet 2011, 377(9770):1019-1031.

6. Li MD, Burmeister M: New insights into the genetics of addiction. Nature reviews 2009, 10(4):225-231.

7. Bierut L: Genetic vulnerability and susceptibility to substance dependence. Neuron 2011, 69(4):618-627.

8. Manolio TA, Brooks LD, Collins FS: A HapMap harvest of insights into the genetics of common disease. The Journal of clinical investigation 2008, 118(5):1590-1605.

9. Epstein DJ: Cis-regulatory mutations in human disease. Briefings in functional genomics \& proteomics 2009, 8(4):310-316.

10. Cookson W, Liang L, Abecasis G, Moffatt M, Lathrop M: Mapping complex disease traits with global gene expression. Nature reviews 2009, 10(3):184-194

11. Pastinen T: Genome-wide allele-specific analysis: insights into regulatory variation. Nature reviews 2010, 11(8):533-538.

12. Cheung VG, Spielman RS, Ewens KG, Weber TM, Morley M, Burdick JT: Mapping determinants of human gene expression by regional and genome-wide association. Nature 2005, 437(7063):1365-1369.

13. Kwan T, Benovoy D, Dias C, Gurd S, Provencher C, Beaulieu P, Hudson TJ, Sladek R, Majewski J: Genome-wide analysis of transcript isoform variation in humans. Nature genetics 2008, 40(2):225-231.

14. Stranger BE, Nica AC, Forrest MS, Dimas A, Bird CP, Beazley C, Ingle CE, Dunning M, Flicek P, Koller D, et al: Population genomics of human gene expression. Nature genetics 2007, 39(10):1217-1224.

15. Cheung VG, Spielman RS: Genetics of human gene expression: mapping DNA variants that influence gene expression. Nature reviews 2009, 10(9):595-604.

16. Myers AJ, Gibbs JR, Webster JA, Rohrer K, Zhao A, Marlowe L, Kaleem M, Leung D, Bryden L, Nath P, et al: A survey of genetic human cortical gene expression. Nature genetics 2007, 39(12):1494-1499.

17. Webster JA, Gibbs JR, Clarke J, Ray M, Zhang W, Holmans P, Rohrer K, Zhao A, Marlowe L, Kaleem M, et al: Genetic control of human brain transcript expression in Alzheimer disease. American journal of human genetics 2009, 84(4):445-458.

18. Liu C, Cheng L, Badner JA, Zhang D, Craig DW, Redman M, Gershon ES: Whole-genome association mapping of gene expression in the human prefrontal cortex. Molecular psychiatry 2010, 15(8):779-784.

19. Singer-Sam J, Chapman V, LeBon JM, Riggs AD: Parental imprinting studied by allele-specific primer extension after PCR: paternal $X$ chromosome-linked genes are transcribed prior to preferential paternal $\mathrm{X}$ chromosome inactivation. Proceedings of the National Academy of Sciences of the United States of America 1992, 89(21):10469-10473.

20. Yan $H$, Yuan W, Velculescu VE, Vogelstein B, Kinzler KW: Allelic variation in human gene expression. Science 2002, 297(5584):1143.

21. Bray NJ, O'Donovan MC: Investigating cis-acting regulatory variation using assays of relative allelic expression. Psychiatric genetics 2006, 16(4):173-177.

22. Bray NJ, Buckland PR, Owen MJ, O'Donovan MC: Cis-acting variation in the expression of a high proportion of genes in human brain. Human genetics 2003, 113(2):149-153.

23. Bray NJ, Buckland PR, Williams NM, Williams HJ, Norton N, Owen MJ, O'Donovan MC: A haplotype implicated in schizophrenia susceptibility is associated with reduced COMT expression in human brain. American journal of human genetics 2003, 73(1):152-161.

24. Bray NJ, Jehu L, Moskvina V, Buxbaum JD, Dracheva S, Haroutunian V, Williams J, Buckland PR, Owen MJ, O'Donovan MC: Allelic expression of APOE in human brain: effects of epsilon status and promoter haplotypes. Human molecular genetics 2004, 13(22):2885-2892. 
25. Bray NJ, Preece A, Williams NM, Moskvina V, Buckland PR, Owen MJ, O'Donovan MC: Haplotypes at the dystrobrevin binding protein 1 (DTNBP1) gene locus mediate risk for schizophrenia through reduced DTNBP1 expression. Human molecular genetics 2005, 14(14):1947-1954.

26. Caffrey TM, Joachim C, Paracchini S, Esiri MM, Wade-Martins R: Haplotypespecific expression of exon 10 at the human MAPT locus. Human molecular genetics 2006, 15(24):3529-3537.

27. Pinsonneault JK, Papp AC, Sadee W: Allelic mRNA expression of X-linked monoamine oxidase a (MAOA) in human brain: dissection of epigenetic and genetic factors. Human molecular genetics 2006, 15(17):2636-2649.

28. Zhang Y, Wang D, Johnson AD, Papp AC, Sadee W: Allelic expression imbalance of human mu opioid receptor (OPRM1) caused by variant A118G. The Journal of biological chemistry 2005, 280(38):32618-32624.

29. Zhang Y, Bertolino A, Fazio L, Blasi G, Rampino A, Romano R, Lee ML, Xiao T, Papp A, Wang D, et al: Polymorphisms in human dopamine D2 receptor gene affect gene expression, splicing, and neuronal activity during working memory. Proceedings of the National Academy of Sciences of the United States of America 2007, 104(51):20552-20557.

30. Lim JE, Papp A, Pinsonneault J, Sadee W, Saffen D: Allelic expression of serotonin transporter (SERT) mRNA in human pons: lack of correlation with the polymorphism SERTLPR. Molecular psychiatry 2006, 11(7):649-662.

31. Lim JE, Pinsonneault J, Sadee W, Saffen D: Tryptophan hydroxylase 2 (TPH2) haplotypes predict levels of TPH2 mRNA expression in human pons. Molecular psychiatry 2007, 12(5):491-501.

32. Yuferov V, Ji F, Nielsen DA, Levran O, Ho A, Morgello S, Shi R, Ott J, Kreek MJ: A functional haplotype implicated in vulnerability to develop cocaine dependence is associated with reduced PDYN expression in human brain. Neuropsychopharmacology 2009, 34(5):1185-1197.

33. Smith RM, Alachkar H, Papp AC, Wang D, Mash DC, Wang JC, Bierut LJ, Sadee W: Nicotinic alpha5 receptor subunit mRNA expression is associated with distant $5^{\prime}$ upstream polymorphisms. Eur J Hum Genet 2011, 19(1):76-83.

34. Pinsonneault JK, Han DD, Burdick KE, Kataki M, Bertolino A, Malhotra AK, Gu HH, Sadee W: Dopamine Transporter Gene Variant Affecting Expression in Human Brain is Associated with Bipolar Disorder. Neuropsychopharmacology 2011, 36(8):1644-1655.

35. Ciobanu DC, Lu L, Mozhui K, Wang X, Jagalur M, Morris JA, Taylor WL, Dietz K, Simon P, Williams RW: Detection, validation, and downstream analysis of allelic variation in gene expression. Genetics 2010, 184(1):119-128.

36. Serre D, Gurd S, Ge B, Sladek R, Sinnett D, Harmsen E, Bibikova M, Chudin E, Barker DL, Dickinson T, et al: Differential allelic expression in the human genome: a robust approach to identify genetic and epigenetic cis-acting mechanisms regulating gene expression. PLoS genetics 2008, 4(2): e1000006.

37. Ge B, Pokholok DK, Kwan T, Grundberg E, Morcos L, Verlaan DJ, Le J, Koka V, Lam KC, Gagne V, et al: Global patterns of cis variation in human cells revealed by high-density allelic expression analysis. Nature genetics 2009, 41(11):1216-1222.

38. Daelemans C, Ritchie ME, Smits G, Abu-Amero S, Sudbery IM, Forrest MS, Campino S, Clark TG, Stanier P, Kwiatkowski D, et al: High-throughput analysis of candidate imprinted genes and allele-specific gene expression in the human term placenta. BMC genetics 2010, 11:25

39. Morcos L, Ge B, Koka V, Lam KC, Pokholok DK, Gunderson KL, Montpetit A, Verlaan DJ, Pastinen T: Genome-wide assessment of imprinted expression in human cells. Genome biology 2011, 12(3):R25.

40. Main BJ, Bickel RD, Mclntyre LM, Graze RM, Calabrese PP, Nuzhdin SV: Allele-specific expression assays using Solexa. BMC genomics 2009, 10:422

41. Zhang K, Li JB, Gao Y, Egli D, Xie B, Deng J, Li Z, Lee JH, Aach J, Leproust EM, et al: Digital RNA allelotyping reveals tissue-specific and allele-specific gene expression in human. Nature methods 2009, 6(8):613-618

42. Lee JH, Park IH, Gao Y, Li JB, Li Z, Daley GQ, Zhang K, Church GM: A robust approach to identifying tissue-specific gene expression regulatory variants using personalized human induced pluripotent stem cells. PLOS genetics 2009, 5(11):e1000718.

43. Mortazavi A, Williams BA, McCue K, Schaeffer L, Wold B: Mapping and quantifying mammalian transcriptomes by RNA-Seq. Nature methods 2008, 5(7):621-628.

44. Wang Z, Gerstein M, Snyder M: RNA-Seq: a revolutionary tool for transcriptomics. Nature reviews 2009, 10(1):57-63.
45. Verlaan DJ, Ge B, Grundberg E, Hoberman R, Lam KC, Koka V, Dias J, Gurd S, Martin NW, Mallmin H, et al: Targeted screening of cis-regulatory variation in human haplotypes. Genome research 2009, 19(1):118-127.

46. Pickrell JK, Marioni JC, Pai AA, Degner JF, Engelhardt BE, Nkadori E, Veyrieras JB, Stephens M, Gilad Y, Pritchard JK: Understanding mechanisms underlying human gene expression variation with RNA sequencing. Nature 2010, 464(7289):768-772.

47. Babak T, Garrett-Engele P, Armour CD, Raymond CK, Keller MP, Chen R, Rohl CA, Johnson JM, Attie AD, Fraser HB, et al: Genetic validation of whole-transcriptome sequencing for mapping expression affected by cis-regulatory variation. BMC genomics 2010, 11:473.

48. Fontanillas P, Landry CR, Wittkopp PJ, Russ C, Gruber JD, Nusbaum C, Hartl DL: Key considerations for measuring allelic expression on a genomic scale using high-throughput sequencing. Molecular ecology 2011, 19(Suppl 1):212-227.

49. Heap GA, Yang JH, Downes K, Healy BC, Hunt KA, Bockett N, Franke L, Dubois PC, Mein CA, Dobson RJ, et al: Genome-wide analysis of allelic expression imbalance in human primary cells by high-throughput transcriptome resequencing. Human molecular genetics 2010, 19(1):122-134.

50. Williams NM, Glaser B, Norton N, Williams H, Pierce T, Moskvina V, Monks S, Del Favero J, Goossens D, Rujescu D, et al: Strong evidence that GNB1L is associated with schizophrenia. Human molecular genetics 2008, 17(4):555-566.

51. Maes OC, Schipper HM, Chong G, Chertkow HM, Wang E: A GSTM3 polymorphism associated with an etiopathogenetic mechanism in Alzheimer disease. Neurobiology of aging 2010, 31(1):34-45.

52. Lo HS, Wang Z, Hu Y, Yang HH, Gere S, Buetow KH, Lee MP: Allelic variation in gene expression is common in the human genome. Genome research 2003, 13(8):1855-1862.

53. Pastinen T, Sladek R, Gurd S, Sammak A, Ge B, Lepage P, Lavergne K, Villeneuve A, Gaudin T, Brandstrom H, et al: A survey of genetic and epigenetic variation affecting human gene expression. Physiological genomics 2004, 16(2):184-193.

54. Johnson AD, Zhang Y, Papp AC, Pinsonneault JK, Lim JE, Saffen D, Dai Z, Wang D, Sadee W: Polymorphisms affecting gene transcription and mRNA processing in pharmacogenetic candidate genes: detection through allelic expression imbalance in human target tissues. Pharmacogenetics and genomics 2008, 18(9):781-791.

55. Richards AL, Jones L, Moskvina V, Kirov G, Gejman PV, Levinson DF, Sanders AR, Purcell S, Visscher PM, Craddock N, et al: Schizophrenia susceptibility alleles are enriched for alleles that affect gene expression in adult human brain. Molecular psychiatry

56. Invernizzi RW: Role of TPH-2 in brain function: news from behavioral and pharmacologic studies. Journal of neuroscience research 2007, 85(14):3030-3035.

57. Haass C, Selkoe DJ: Soluble protein oligomers in neurodegeneration: lessons from the Alzheimer's amyloid beta-peptide. Nat Rev Mol Cell Biol 2007, 8(2):101-112.

58. Singleton A, Myers A, Hardy J: The law of mass action applied to neurodegenerative disease: a hypothesis concerning the etiology and pathogenesis of complex diseases. Human molecular genetics 2004, 13(Spec No 1):R123-126.

59. Brouwers N, Sleegers K, Engelborghs S, Bogaerts V, Serneels S, Kamali K, Corsmit E, De Leenheir E, Martin JJ, De Deyn PP, et al: Genetic risk and transcriptional variability of amyloid precursor protein in Alzheimer's disease. Brain 2006, 129(Pt 11):2984-2991.

60. Horan M, Millar DS, Hedderich J, Lewis G, Newsway V, Mo N, Fryklund L, Procter AM, Krawczak M, Cooper DN: Human growth hormone $1(\mathrm{GH} 1)$ gene expression: complex haplotype-dependent influence of polymorphic variation in the proximal promoter and locus control region. Human mutation 2003, 21(4):408-423.

61. Tao H, Cox DR, Frazer KA: Allele-specific KRT1 expression is a complex trait. PLoS genetics 2006, 2(6):e93.

62. Babbitt CC, Silverman JS, Haygood R, Reininga JM, Rockman MV, Wray GA: Multiple Functional Variants in cis Modulate PDYN Expression. Molecular biology and evolution 2010, 27(2):465-479.

63. Buonocore F, Hill MJ, Campbell CD, Oladimeji PB, Jeffries AR, Troakes C, Hortobagyi T, Williams BP, Cooper JD, Bray NJ: Effects of cis-regulatory variation differ across regions of the adult human brain. Human molecular genetics 2010, 19(22):4490-4496. 
64. Kwan T, Benovoy D, Dias C, Gurd S, Serre D, Zuzan H, Clark TA, Schweitzer A, Staples MK, Wang H, et al: Heritability of alternative splicing in the human genome. Genome research 2007, 17(8):1210-1218.

65. Lalonde E, Ha KC, Wang Z, Bemmo A, Kleinman CL, Kwan T, Pastinen T, Majewski J: RNA sequencing reveals the role of splicing polymorphisms in regulating human gene expression. Genome research 2010, 21(4):545-554.

66. McDaniell R, Lee BK, Song L, Liu Z, Boyle AP, Erdos MR, Scott L, Morken MA, Kucera KS, Battenhouse A, et al: Heritable individual-specific and allele-specific chromatin signatures in humans. Science 2010, 328(5975):235-239

67. Tycko B: Allele-specific DNA methylation: beyond imprinting. Human molecular genetics 2010, 19(R2):R210-220.

68. Craig DW, Pearson JV, Szelinger S, Sekar A, Redman M, Corneveaux JJ, Pawlowski TL, Laub T, Nunn G, Stephan DA, et al: Identification of genetic variants using bar-coded multiplexed sequencing. Nature methods 2008 , 5(10):887-893.

69. Edgar RC: MUSCLE: multiple sequence alignment with high accuracy and high throughput. Nucleic acids research 2004, 32(5):1792-1797.

doi:10.1186/1471-2164-12-518

Cite this article as: Xu et al.: Next-generation DNA sequencing-based assay for measuring allelic expression imbalance (AEI) of candidate neuropsychiatric disorder genes in human brain. BMC Genomics 2011 12:518.

\section{Submit your next manuscript to BioMed Central} and take full advantage of:

- Convenient online submission

- Thorough peer review

- No space constraints or color figure charges

- Immediate publication on acceptance

- Inclusion in PubMed, CAS, Scopus and Google Scholar

- Research which is freely available for redistribution

Submit your manuscript at www.biomedcentral.com/submit 